IJHER International Journal of Humanities and Educational Research ISSN: 2757-5403

Volume 4, Issue 1, February 2022

Received: $12 / 12 / 2021$

Accepted: 03/01/2022

Published: 01/02/2022

\title{
THE FIRST DIRECT ELECTIONS OF THE IRAQI PARLIAMENT ON JANUARY 17,1953 IN U.S.A. SECRET DOCUMENTS, PUBLISHED FOR THE FIRST TIME
}

\author{
Mohammed H. Kuter AL RABAY 1 \\ Dr, Mustansiriyah University, Iraq
}

\begin{abstract}
This research entitled with ' the Iraqi Parliament first elections on 17 January,1953 as tackled by the classified US documents published for the first time.'

It examined the classified reports and cables sent by the US Embassy in Baghdad and its consulate in Basra to the US Department of State between October,1952 until the end of the elections on 17 January, 1953.

The thorough study of the documents disclosed how the US Embassy went far in its intervention in the Iraqi internal affairs to convey a clear idea to the US Department on the Iraqi political landscape and parties that won the direct elections and to increase its domination on Iraq at that time.
\end{abstract}

Key words: Elections, Documents, American, Secret, First.

http://dx.doi.org/10.47832/2757-5403.12.18

1 (D) drmohmedhushimalrobyeai@gmail.com 


\title{
الانتخابات المباشرة الأولى لمجلس النواب العراقي 17 كانون الثاني 1953 في وثائق سريّة أمريكية تُشنر للمرة الأولى النى
}

محمد هاشم خويطر الربيعي

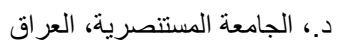

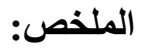

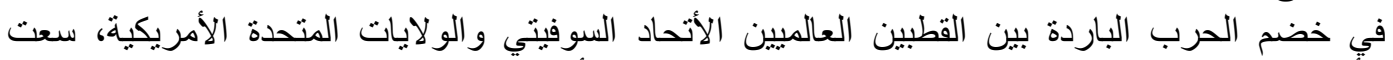

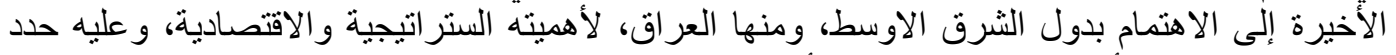

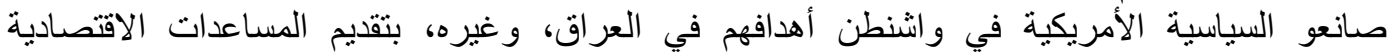

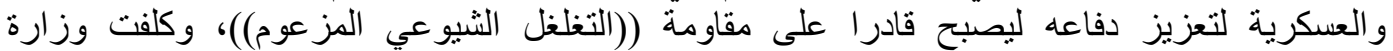

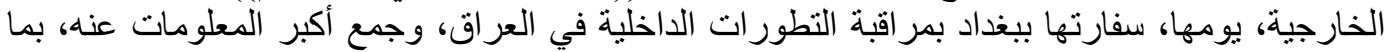

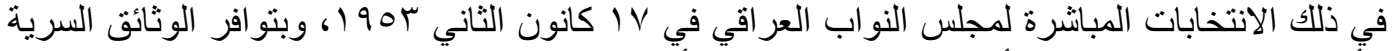

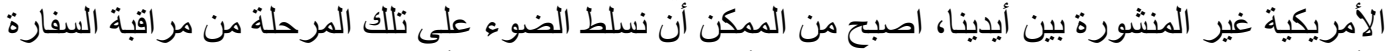

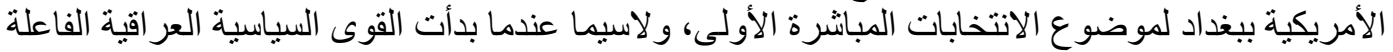

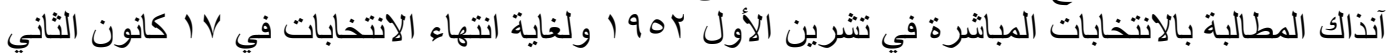

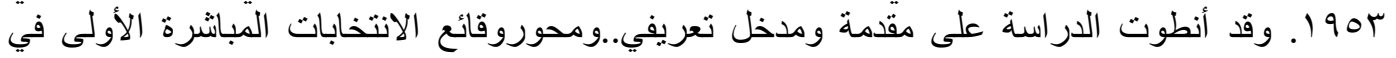

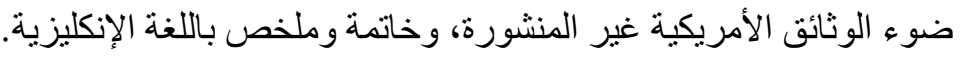

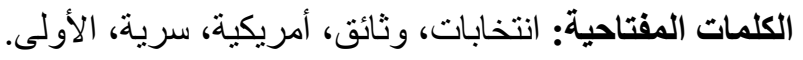

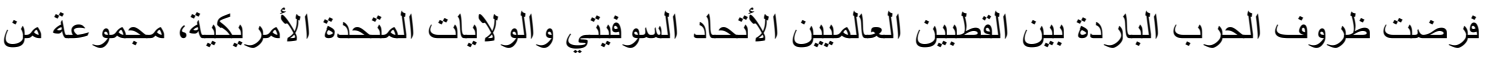

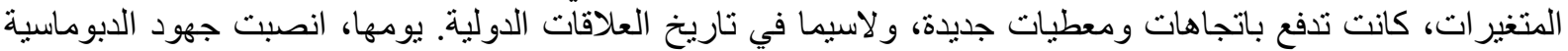

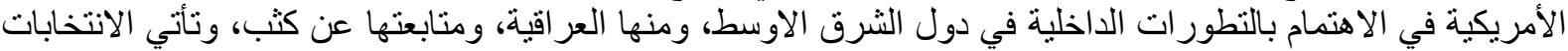

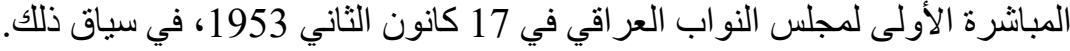

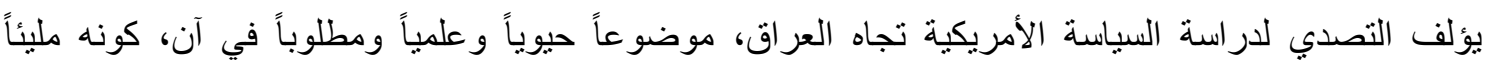

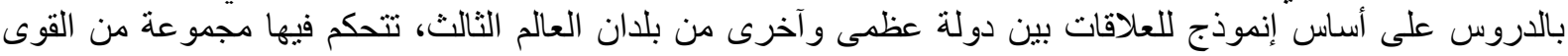

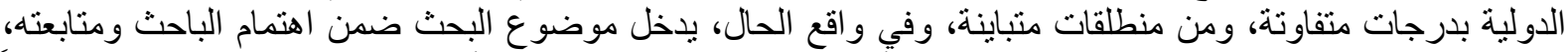

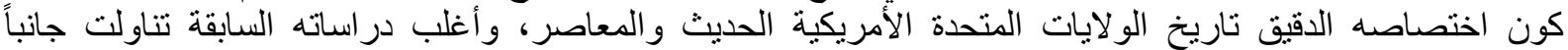

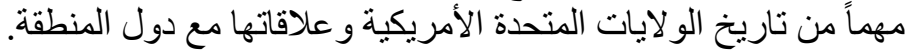

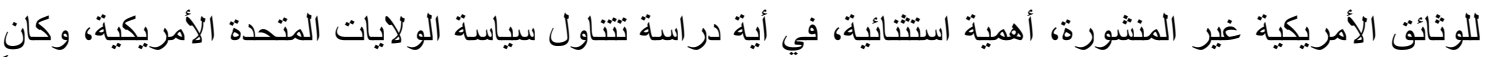

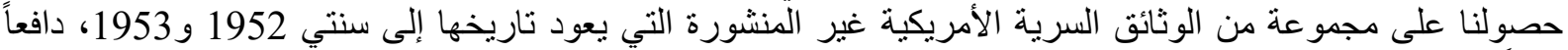

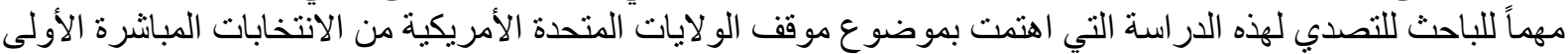

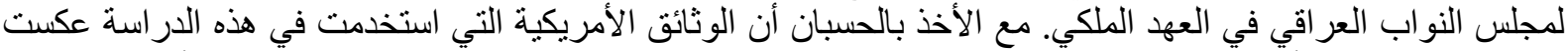

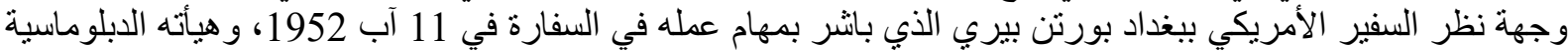
بما في ذللك قنصليتها في البصرة.

مدخل تعريفي:

ضم القانون الأساسي العر اقي (الدستور) (صادق عليه المجلس التأسيسي العر اقي في 10 تموز 1923 1924، وتم نشره

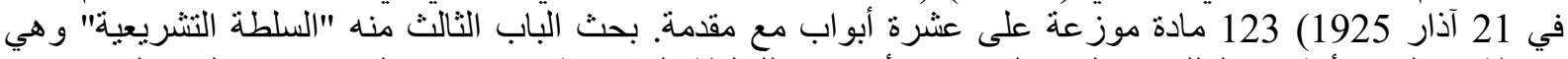

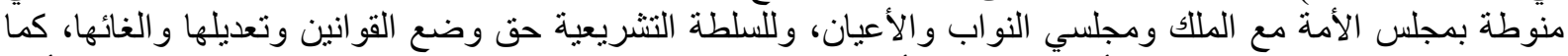

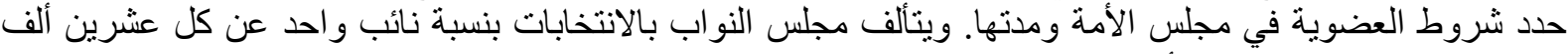

نسمة من الذكور، اما مجلس الأعيان فيعين اعضاؤه من قبل المبل الملك (1). 
وتبع مصادقة المجلس التأسيسي العر اقي على الدستور في عهد الملك فيصل الأول (1921 1933) 1924)، تشريع قانون

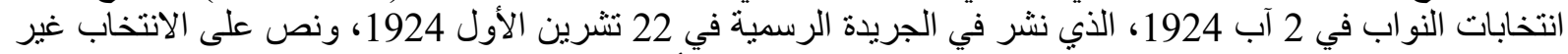

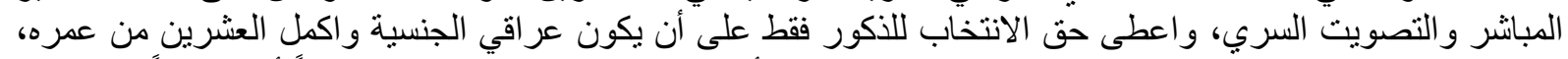

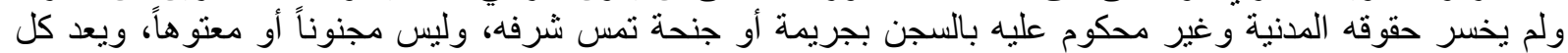
المواطنين الذين تتوفر فيهم الشروط "منتخبون اولون"، يستطيعون أن يصوتوا للمنتخبين الثين الثانويين، ويقابل كل منتخب

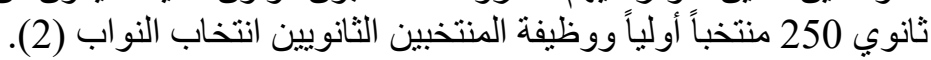

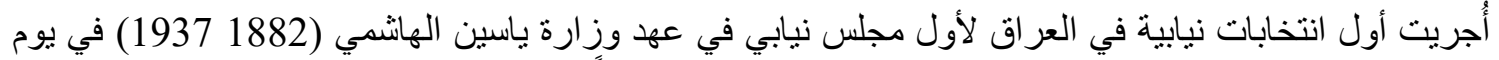

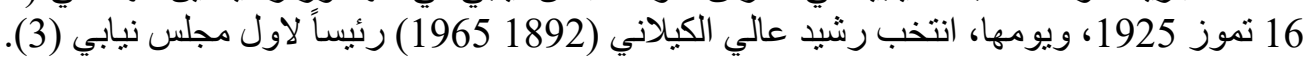

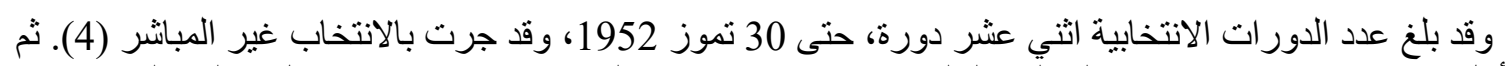

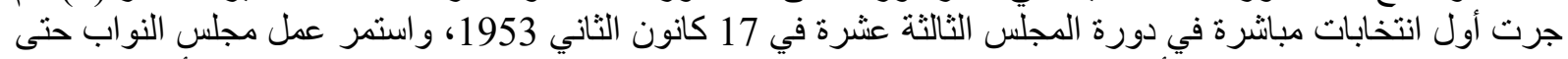

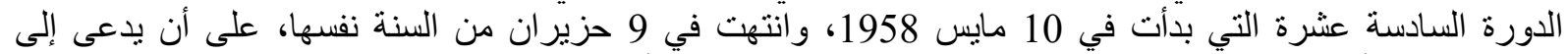

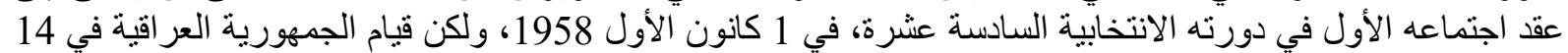

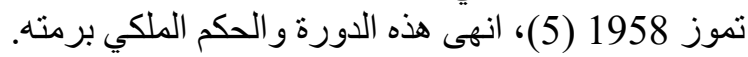

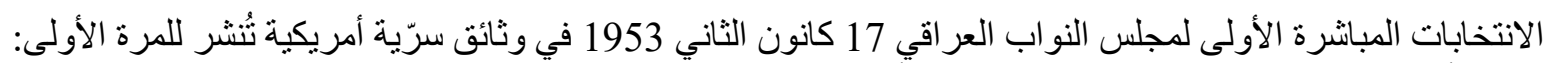

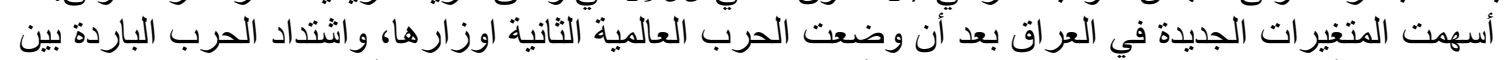

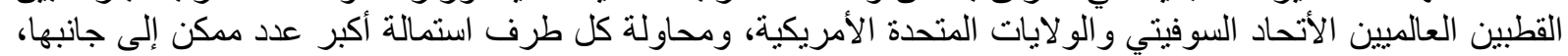

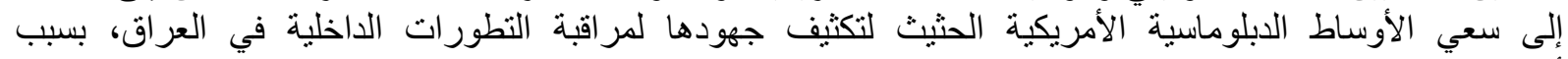
أهميته الستر اتيجية و الاقتصادية الاستثنائية.

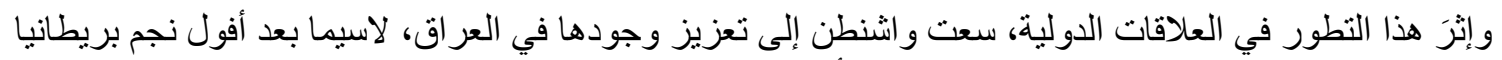

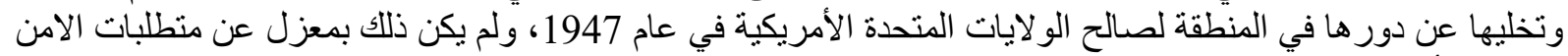

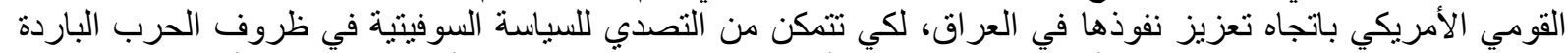

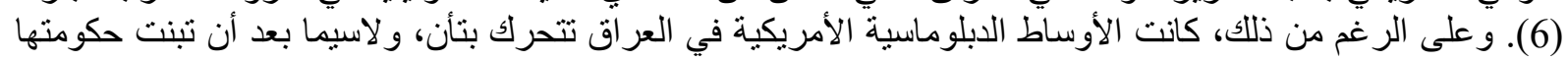

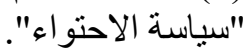

في ضوء ما تقام، حدد صانعو السياسة الأمريكية، اهدافهم في دول الثرق الأوسط، ومنها الأها العراق في حزيران

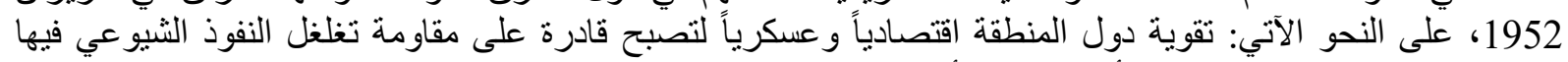

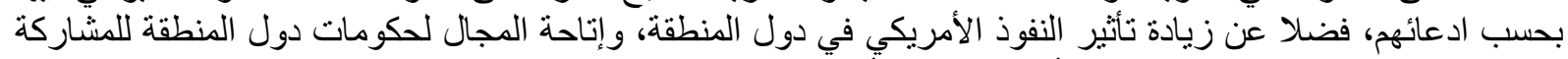

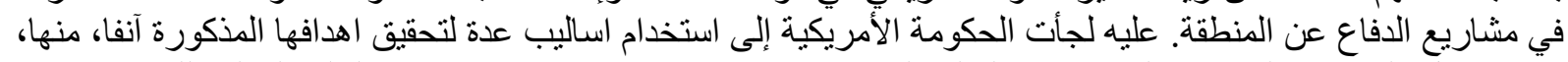

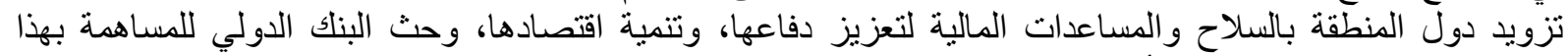

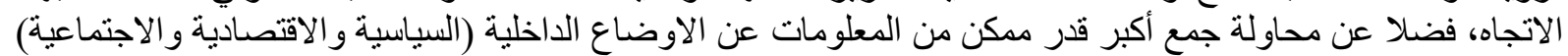

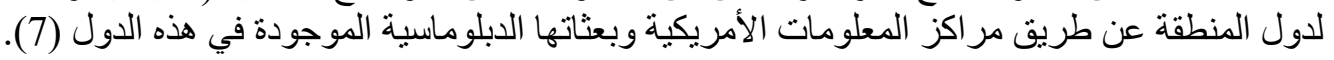

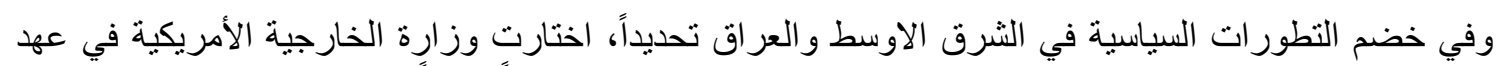

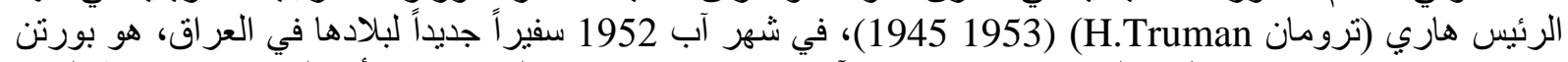

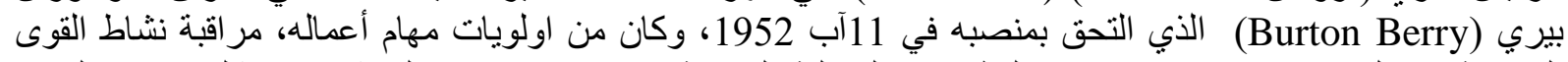

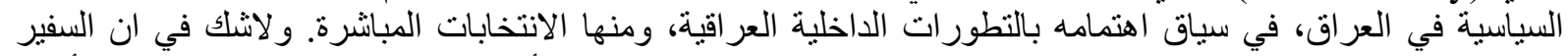

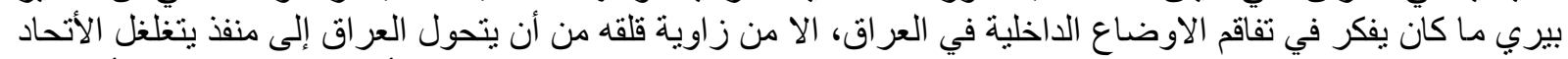

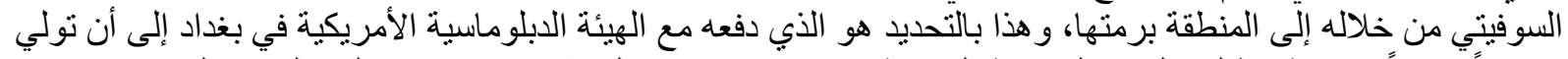

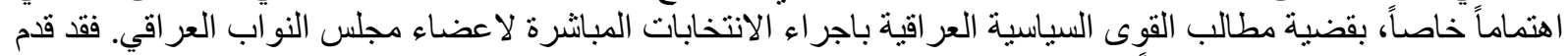

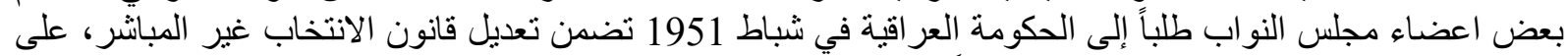

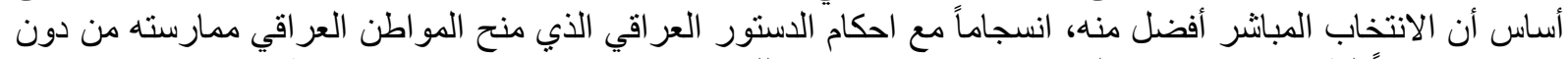

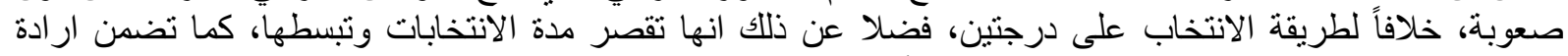

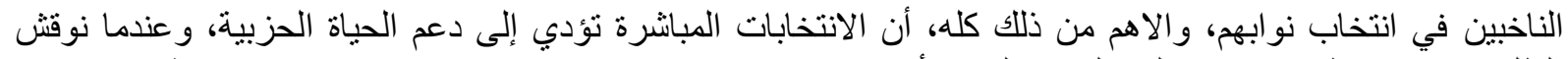

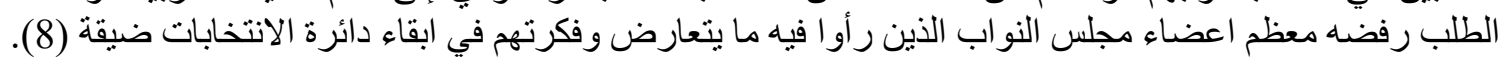

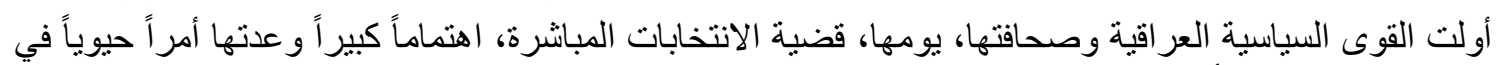

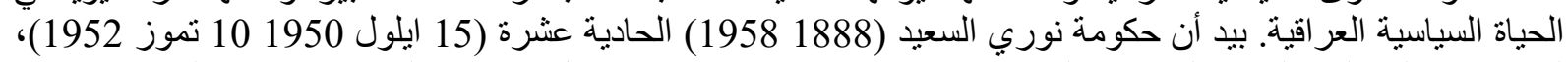

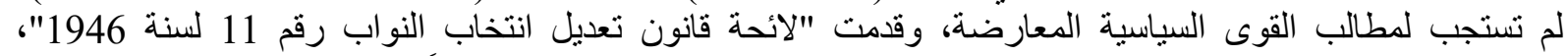

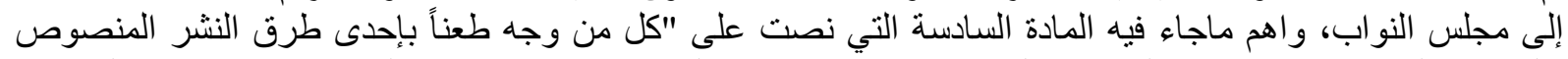

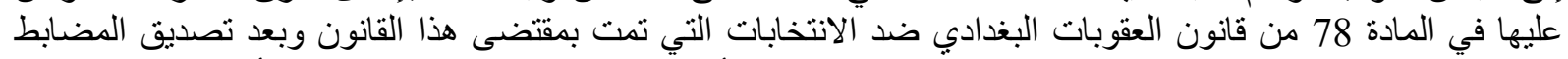

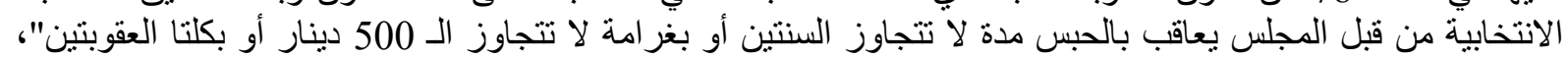

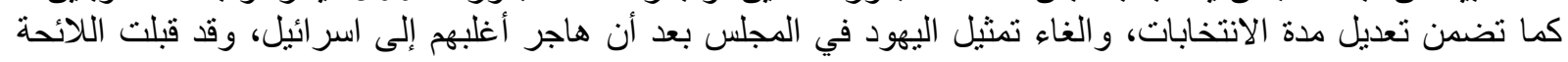




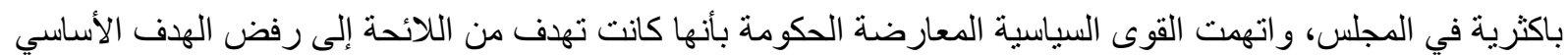

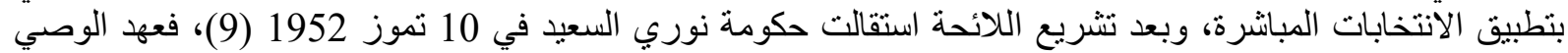

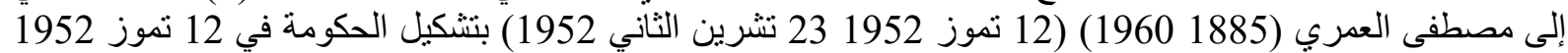

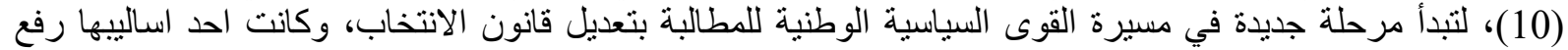

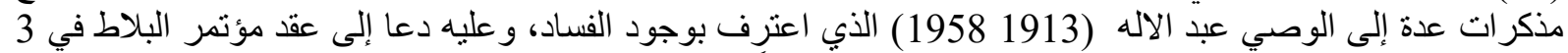

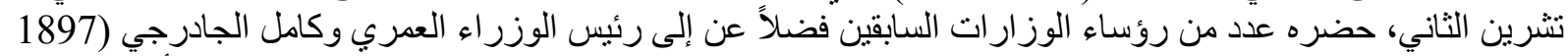

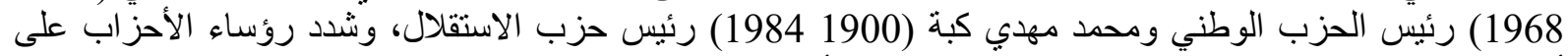

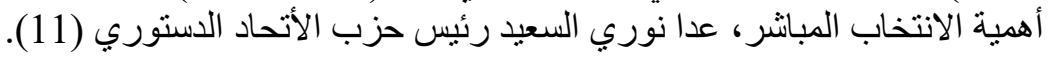

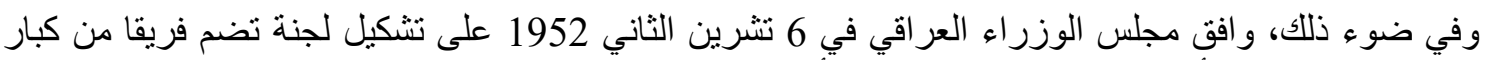

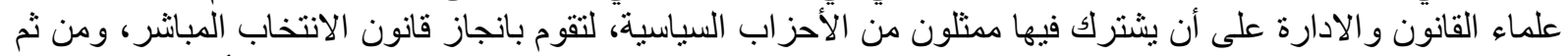

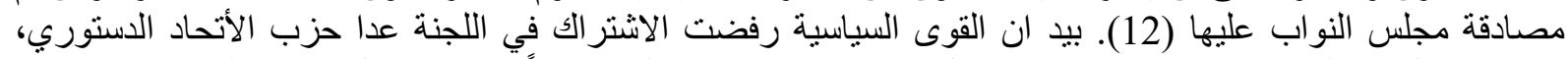

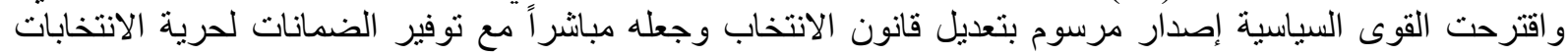

كان هذا التقاطع بين القوى السياسية المعارضة والحكومة العر اقية بداية لانطلاق انتفاضة تشرين الثاني 1952 التي

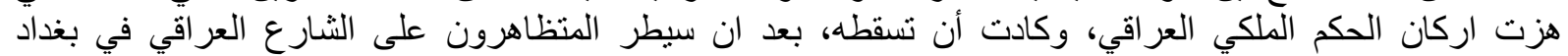

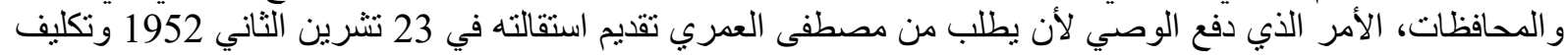

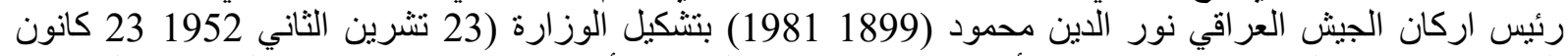

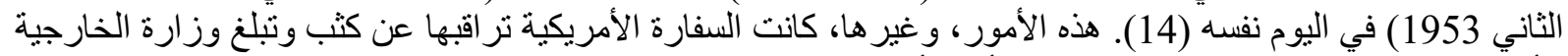

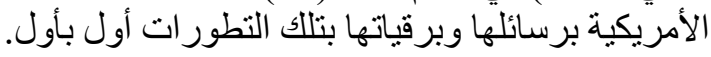

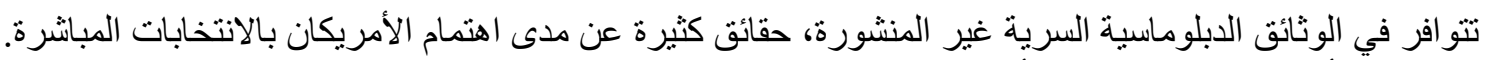

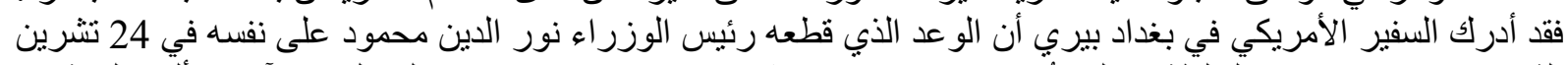

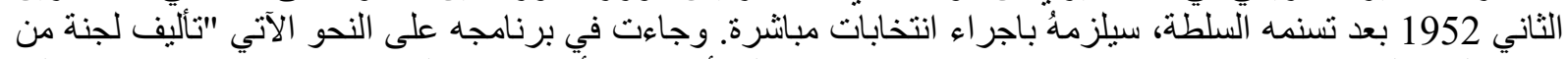

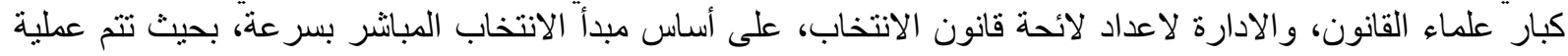
الانتخاب التي ستقوم بها هذه الحكومة"، التي سترفع قبل الانتخابات، الاحكام العرفية التي فرضت في لوان الأو (محافظة) بغداد

ومن المهم أن نشير هنا، إلى أن السفارة الأمريكية تابعت قضية الانتخابات حتى قبل تسنم نور الدين الإني محمود سدة

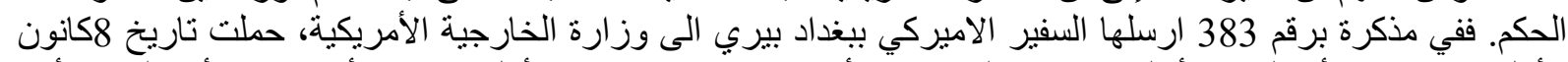

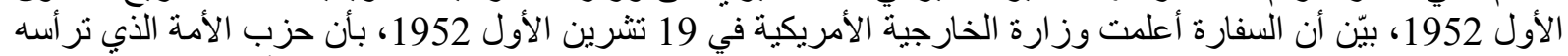

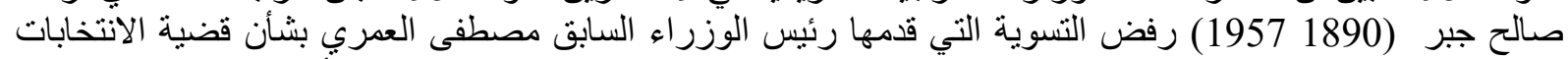

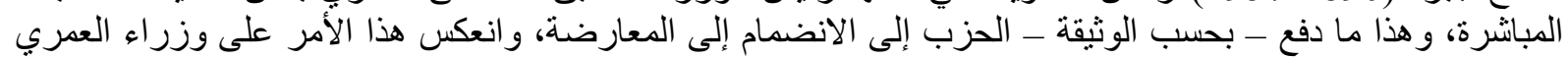

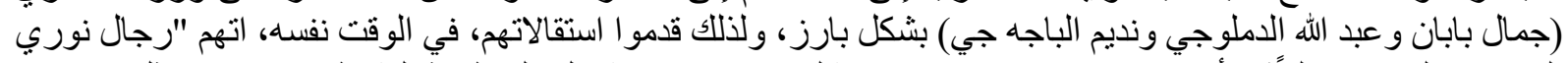

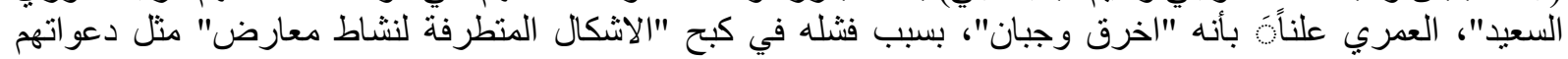

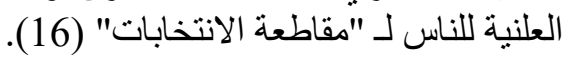

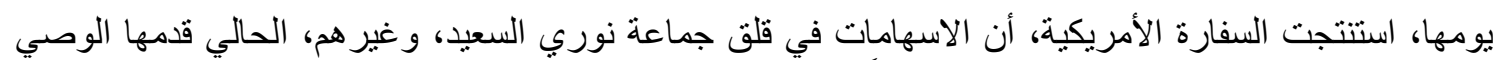

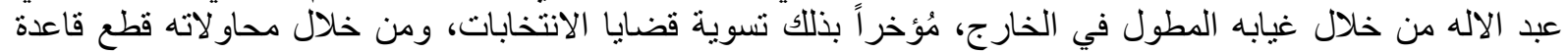

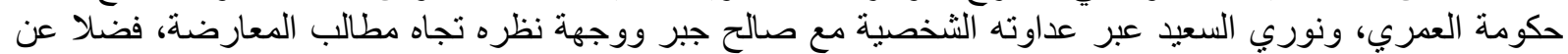

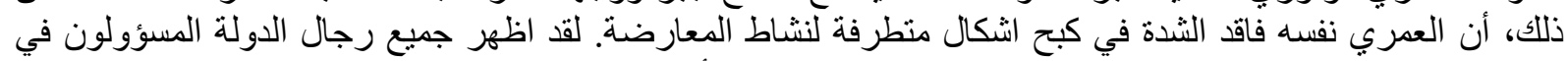

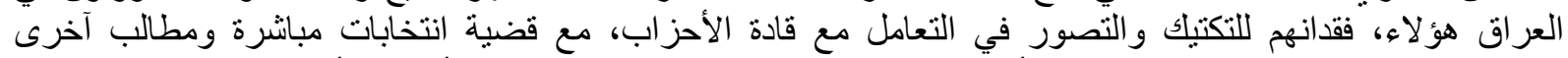

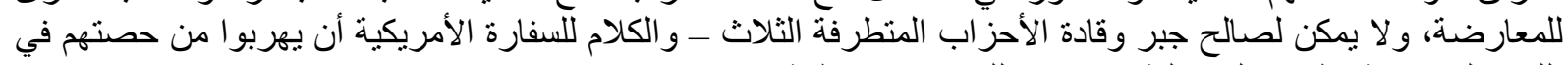

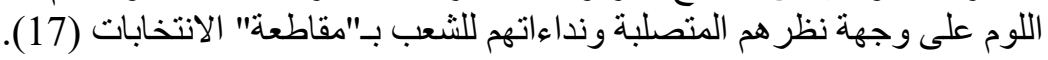

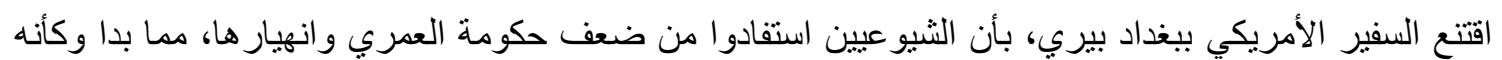

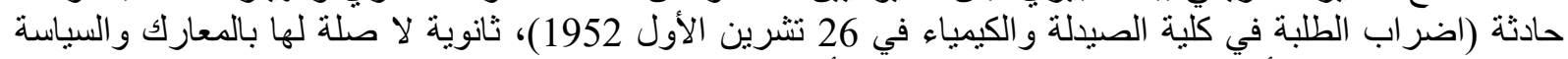

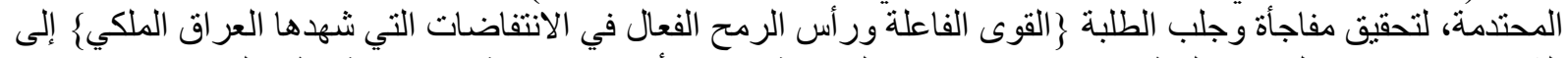

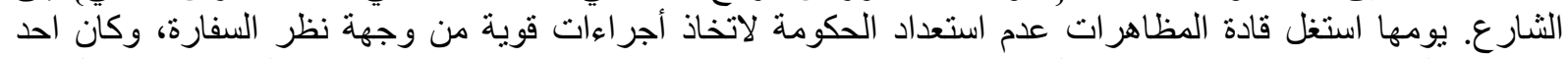

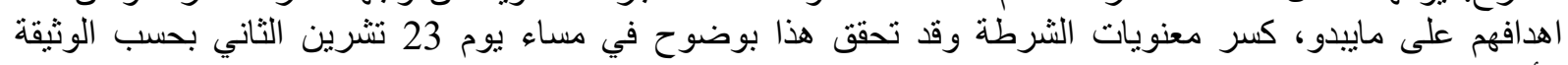

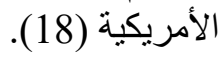

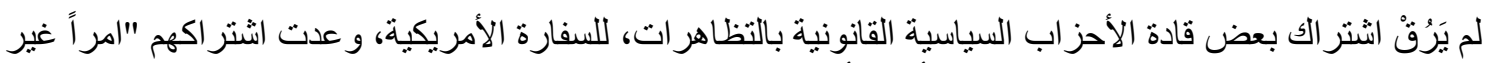

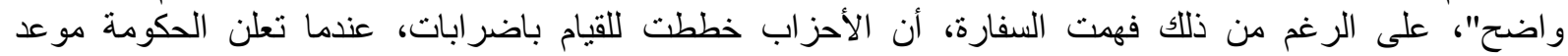

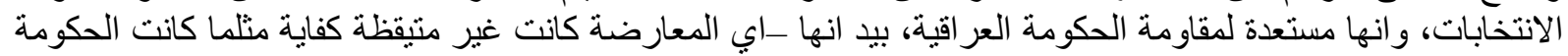




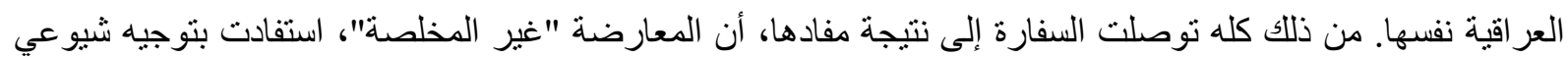

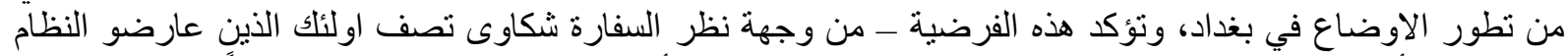

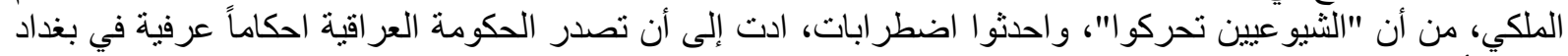

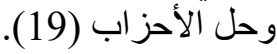

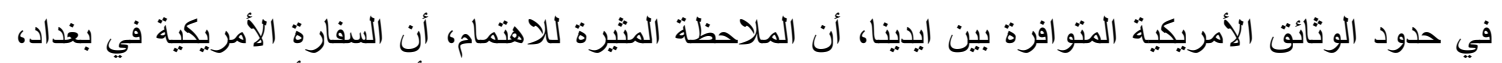

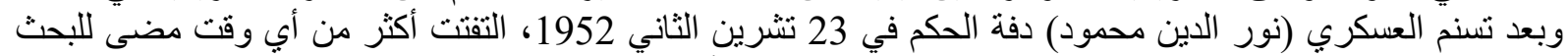

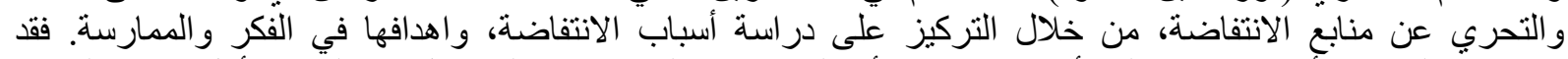

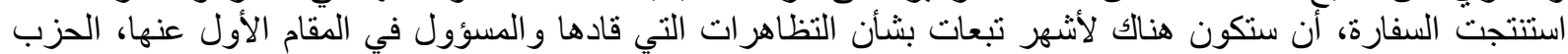

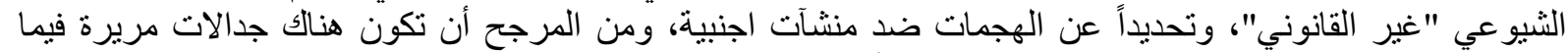

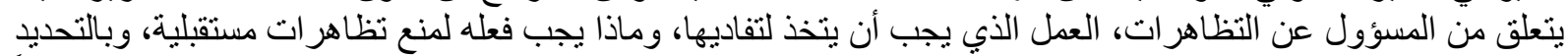

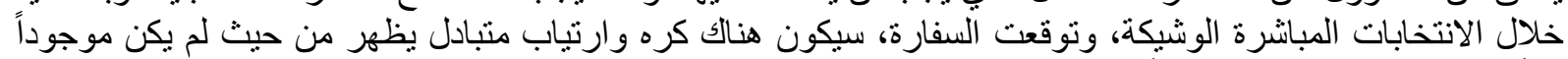

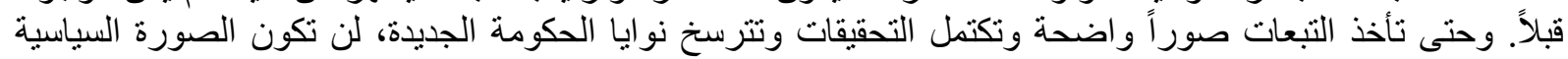

و اضحة (20).

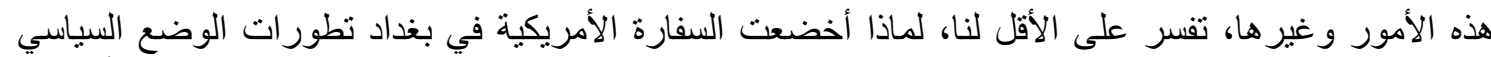

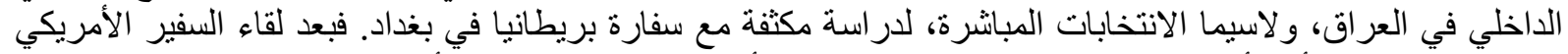

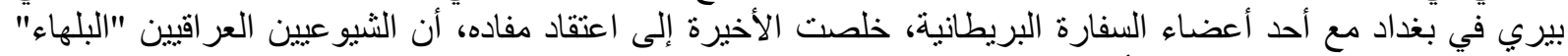

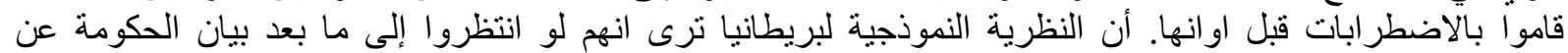

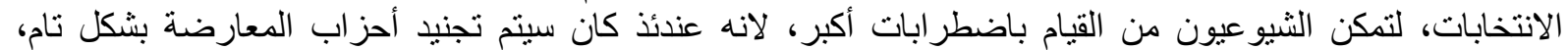

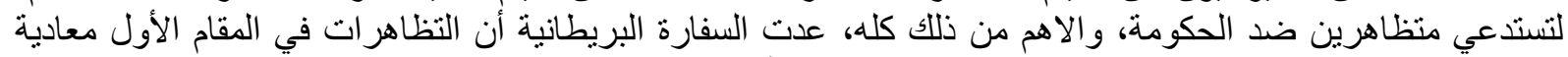

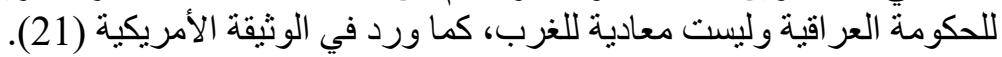

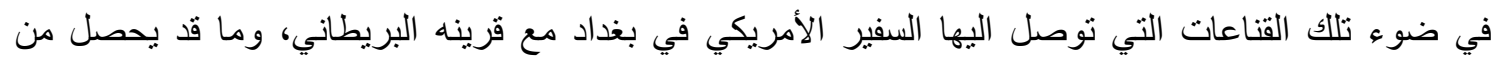

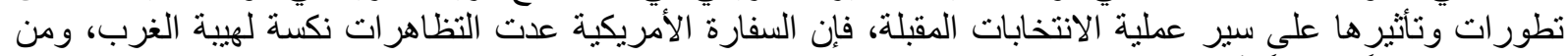

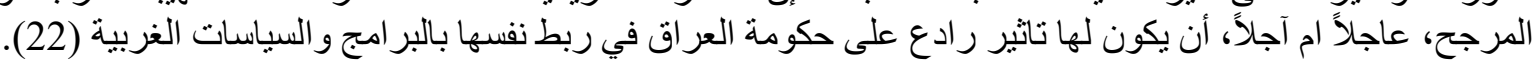

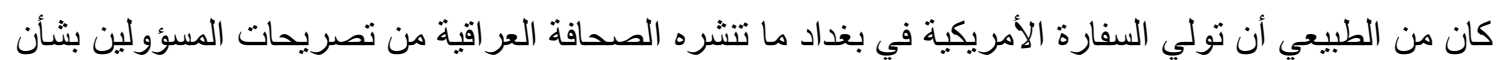

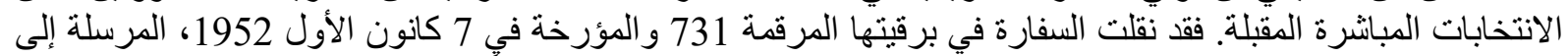

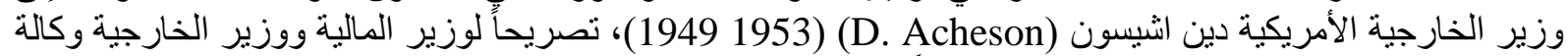

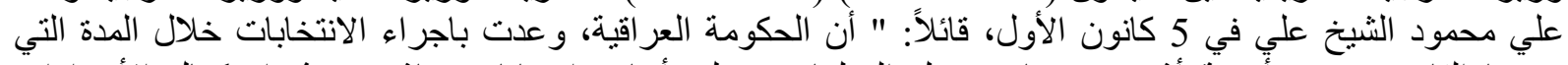

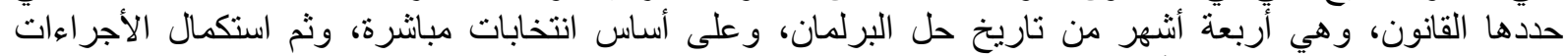
وسيصدر قانون بهذا خلال 10 أيام" (23).

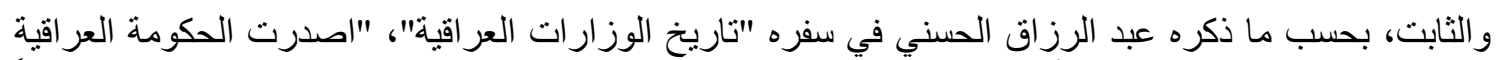

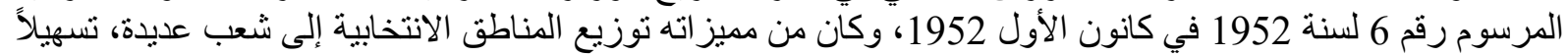

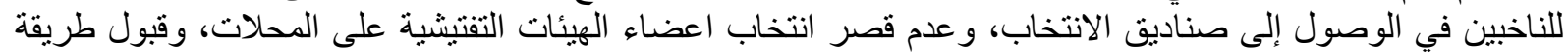

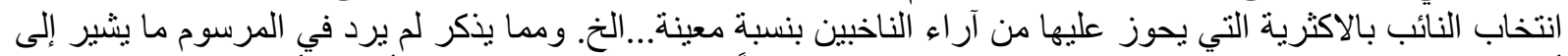

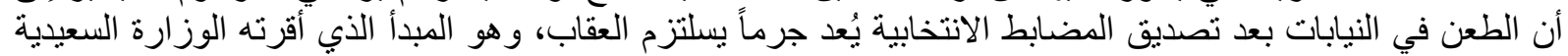

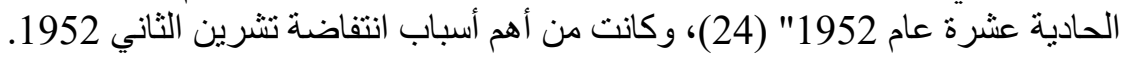

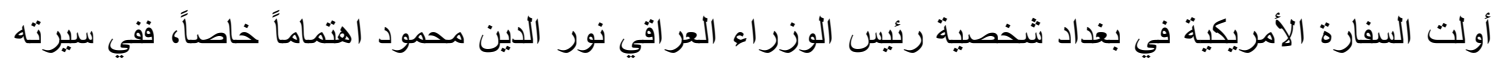

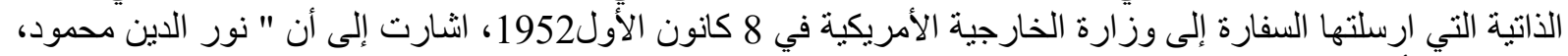

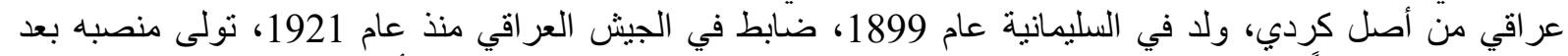

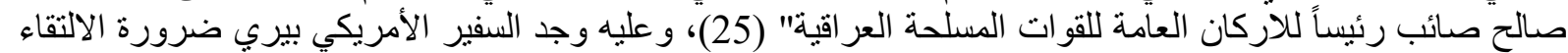

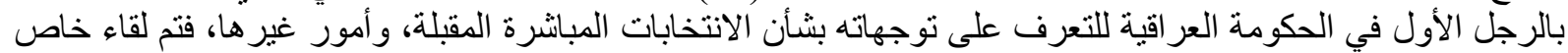

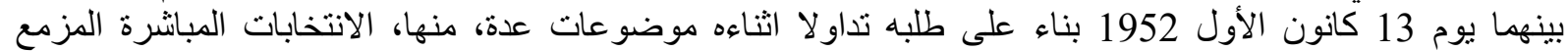

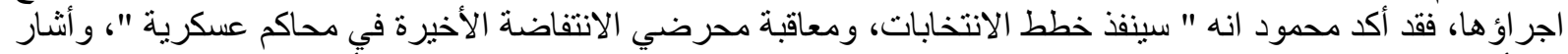

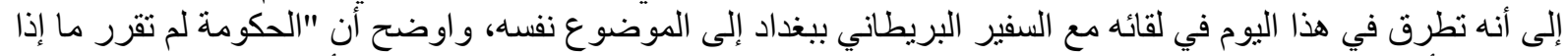

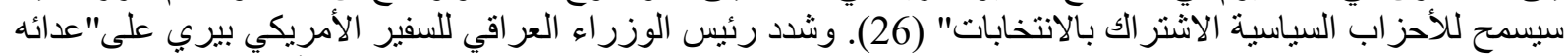

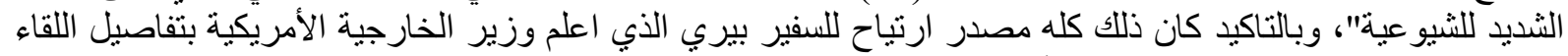

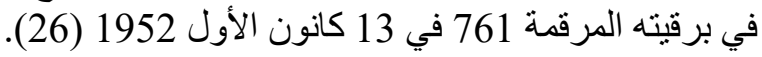

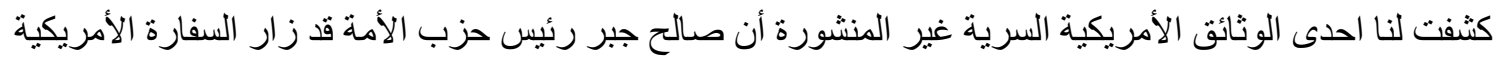

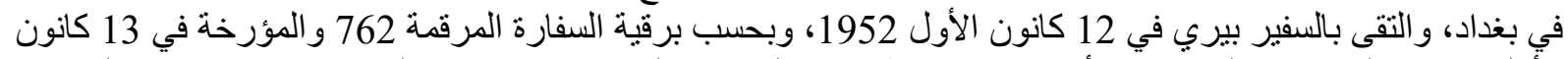

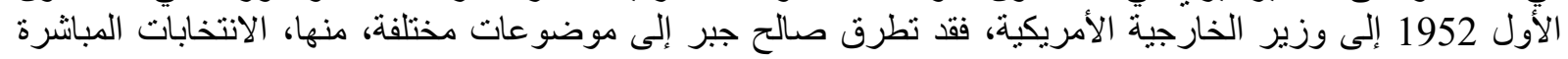




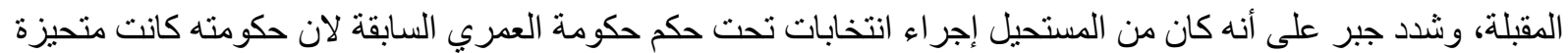

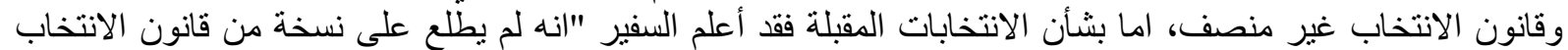

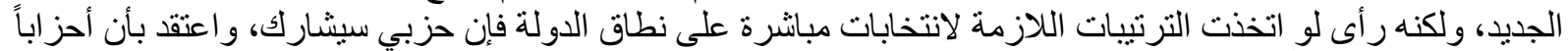

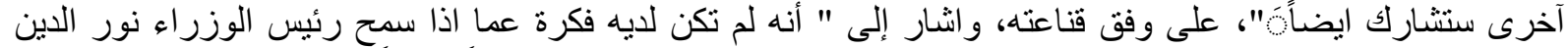

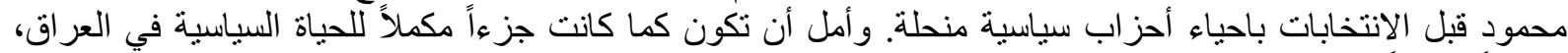

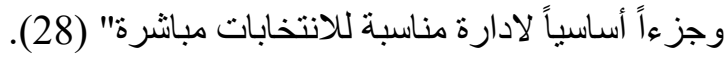

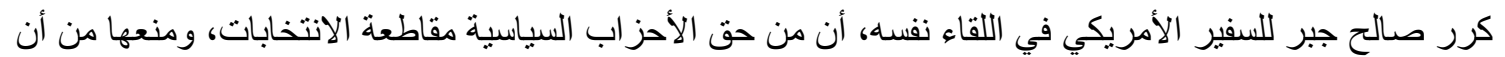

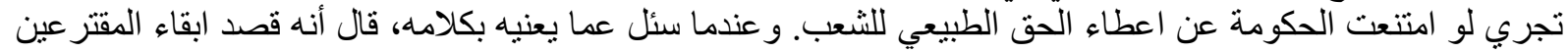

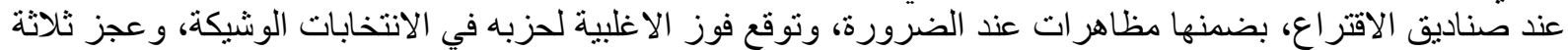

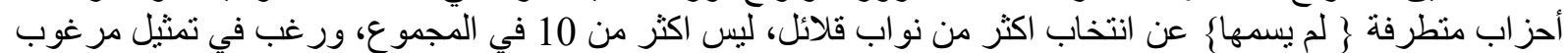

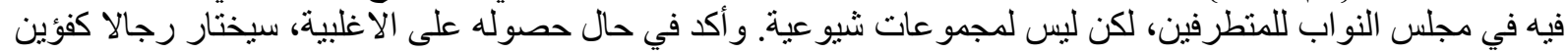

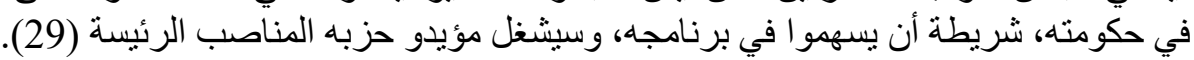

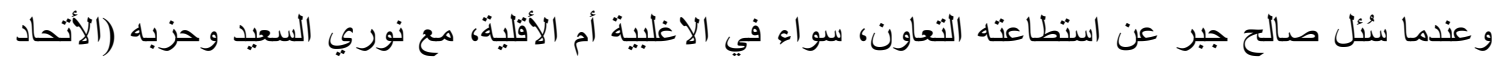

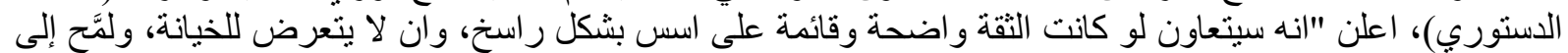

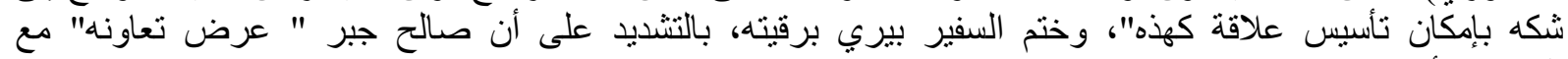

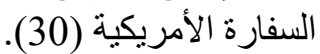

وفي الاطار نفسه، أولى الأمريكان الموقف الرسمي والأعلامي البريطاني من الانتخابات المباثرة المقبلة لمجلس

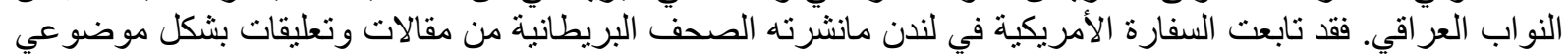

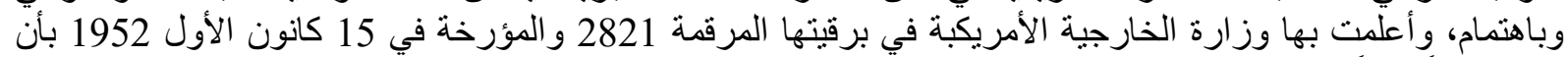

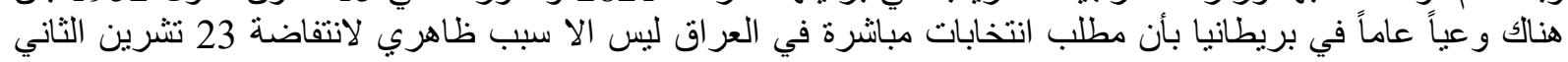

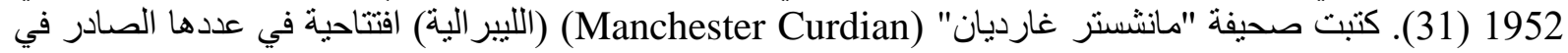

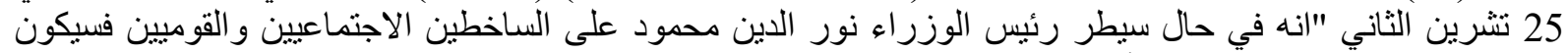

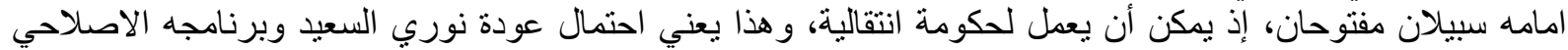

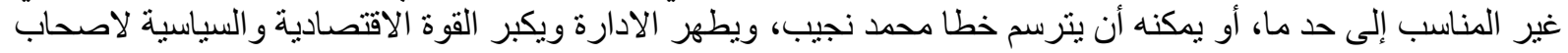

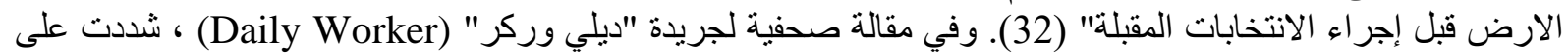

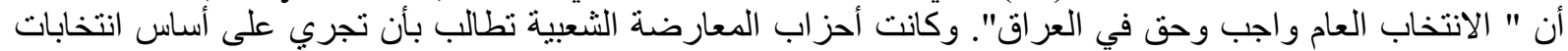

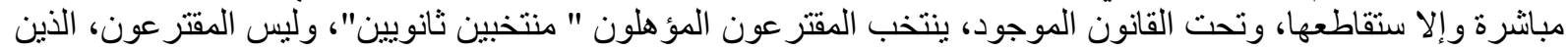

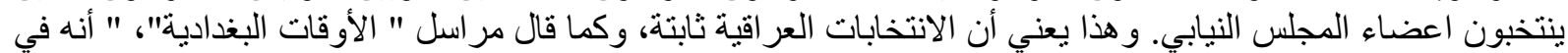

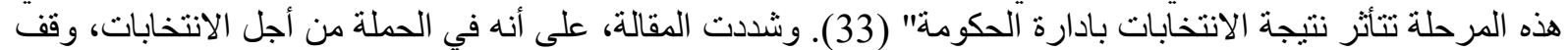

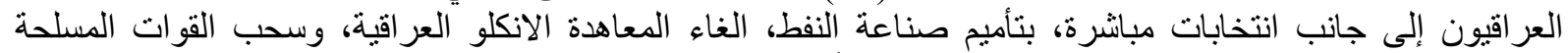

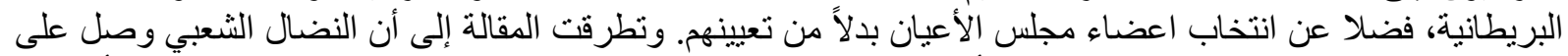

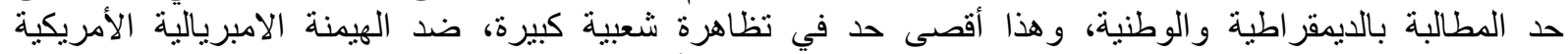

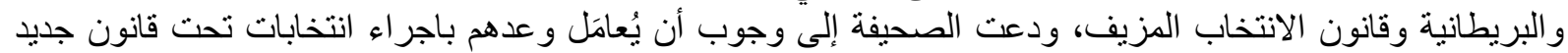

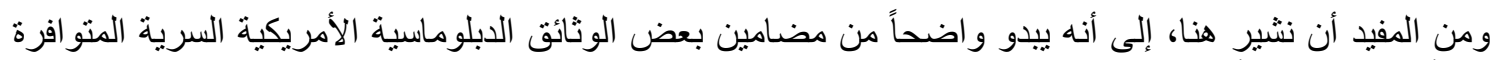

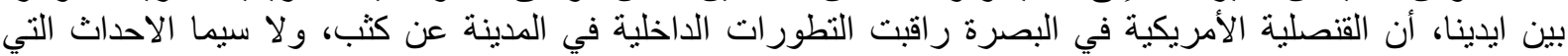

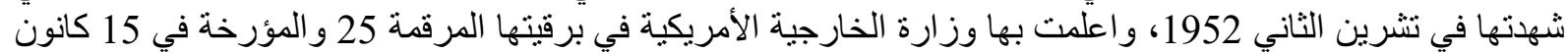

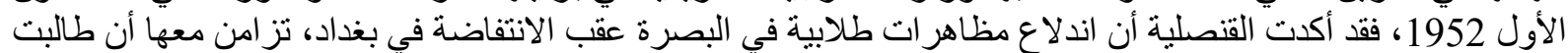

الصحف البصرية المعارضة لككومة العمري بانتخابات مبانشرة في العر اق القاب (35).

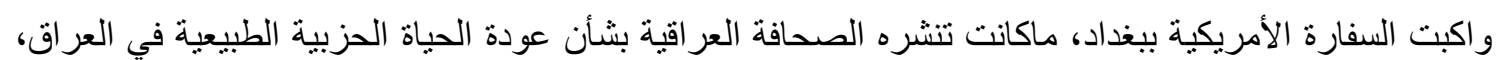

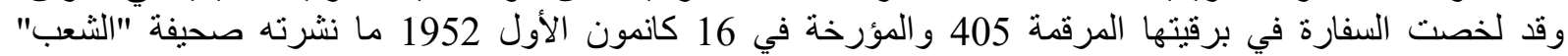

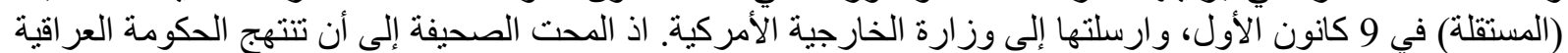
سياسة الاسترضاء تجاه الأحز اب السياسية العر اقية من أجل استئناف حياة حزبية طبية النية النية في العراق (36).

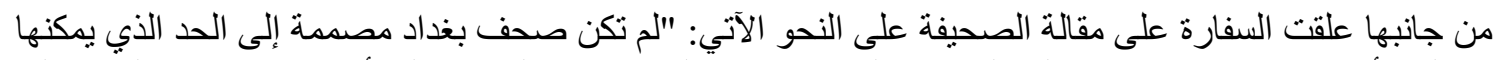

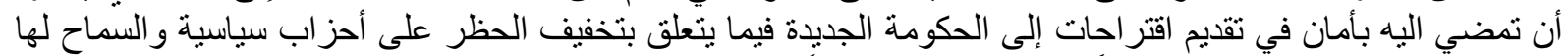

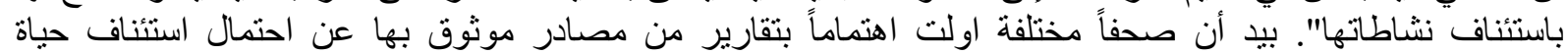

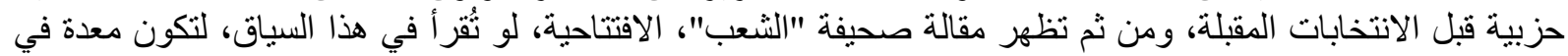

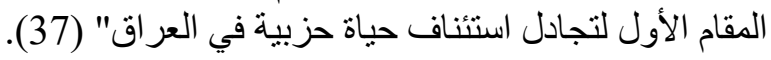


حسبما تروي البرقية الصادرة من السفارة الأمريكية ببغداد إلى وزارة التارة الخارجية الأمريكية، و المرقمة 814

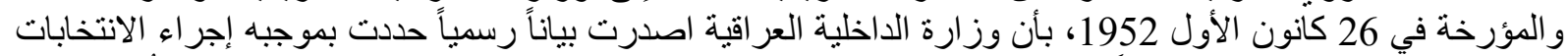

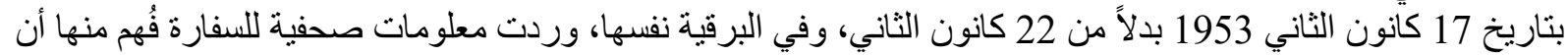

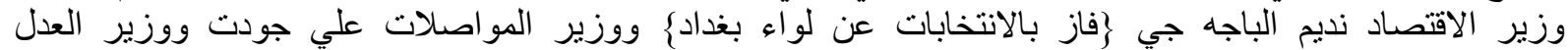
عبد الرسول الخالصي \}فاز بالانتخابات عن لو اء بغدادئ كانو اليخططون للإخول في حملة انتخابية للترشيح في الانتخابات

المقبلة، في حين لم يرشح اعضاء الوزي الوزارة (38).

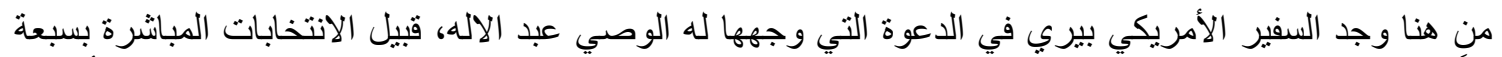

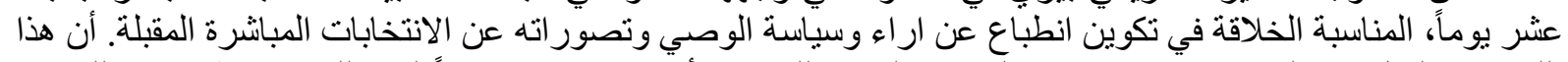

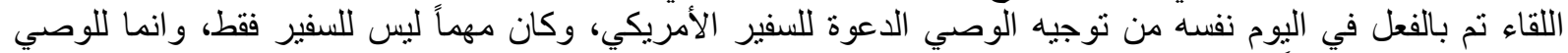

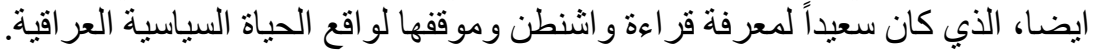

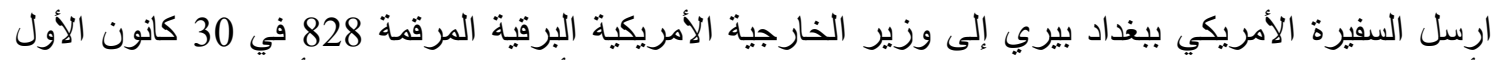

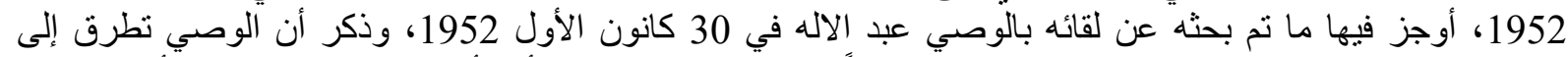

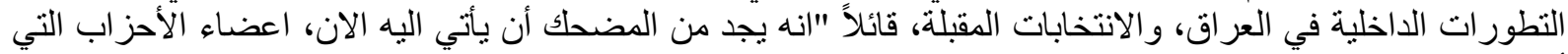

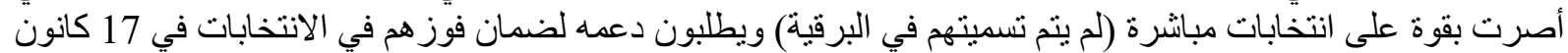

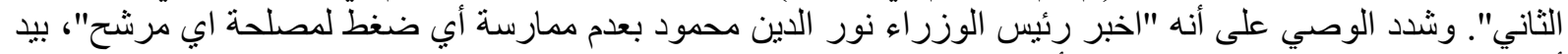

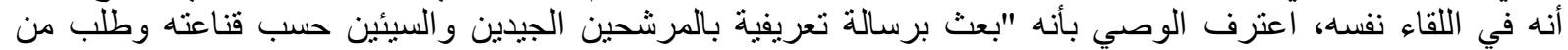

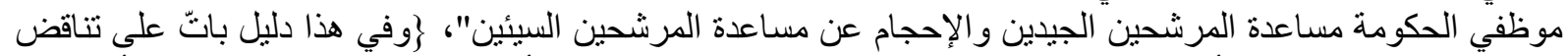

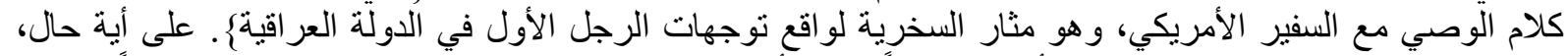

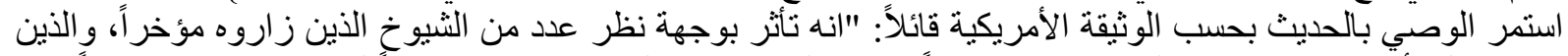

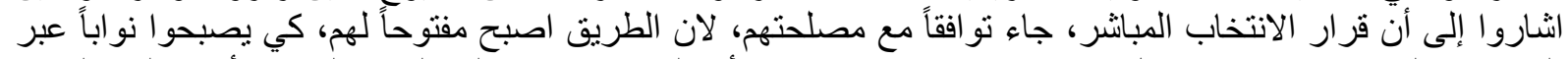

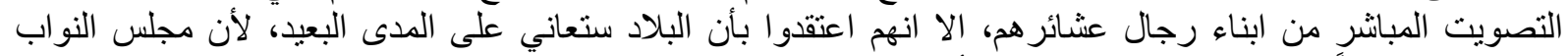

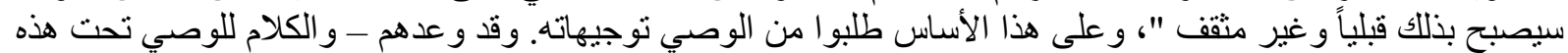

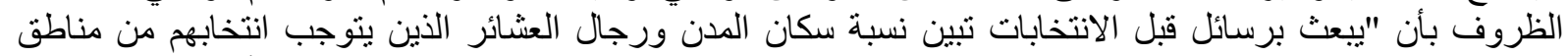

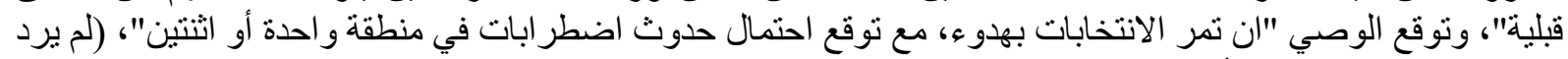
اسميهما في نص الوثيقة الأمريكية) (39).

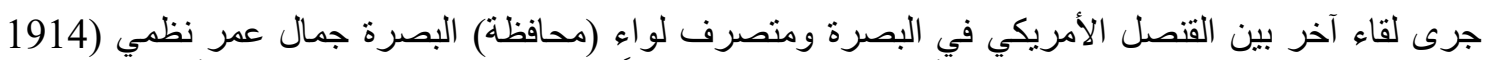

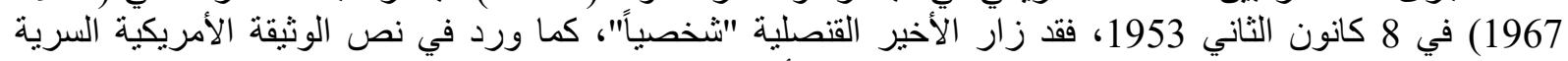

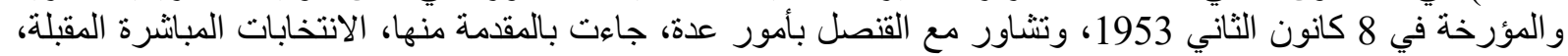

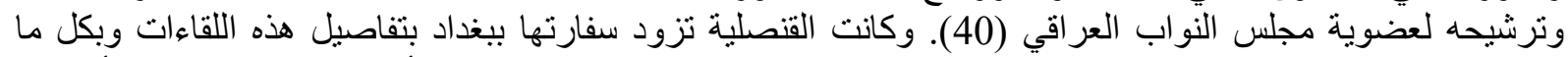

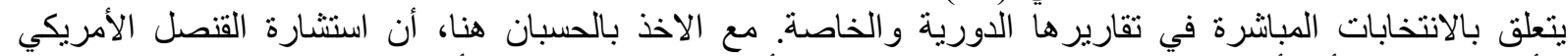

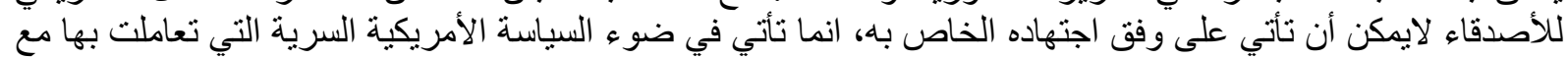

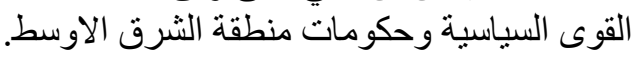

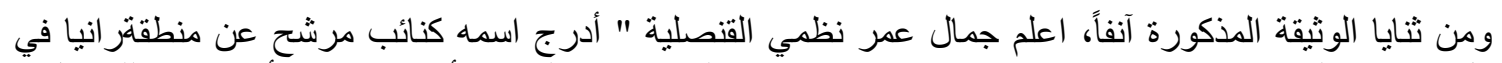

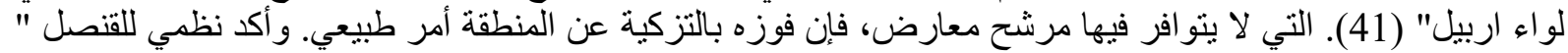

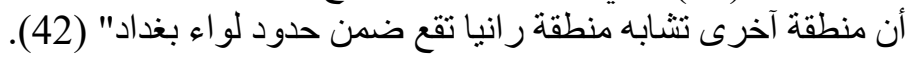

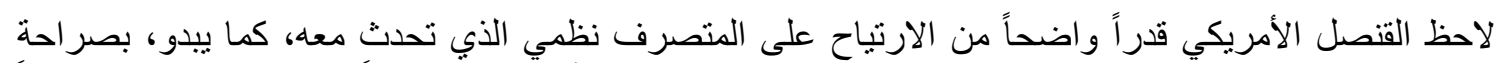

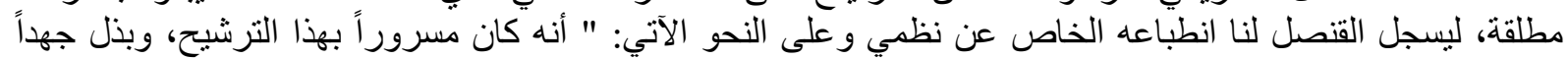

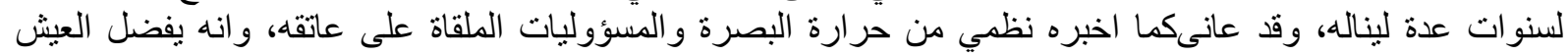

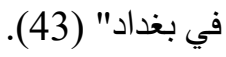

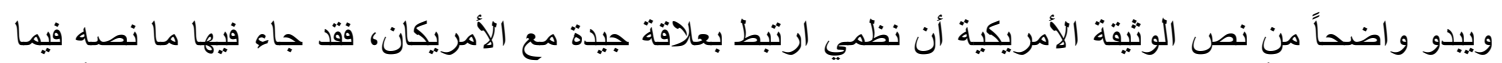

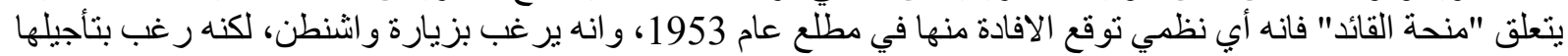

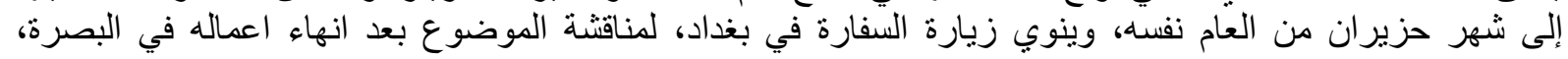

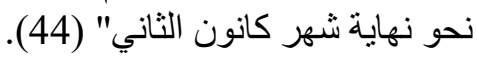

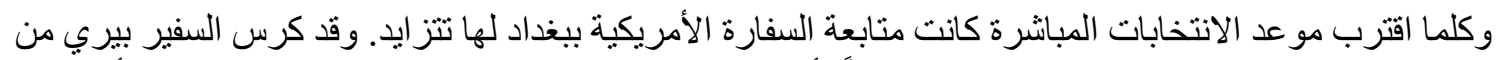

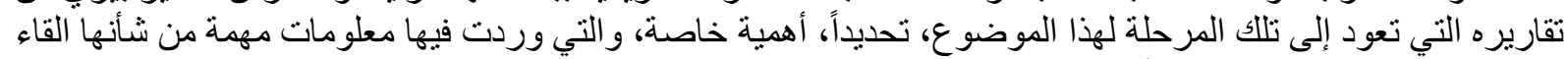

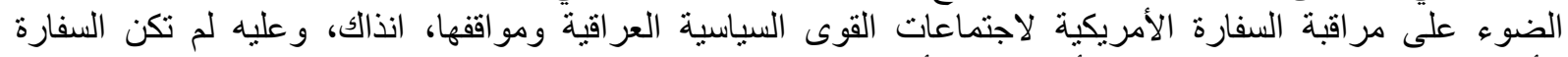

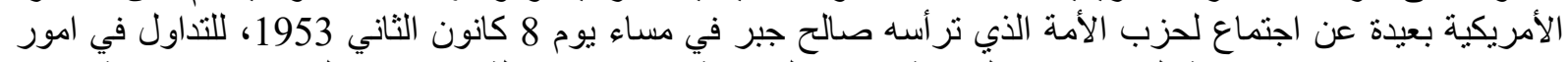

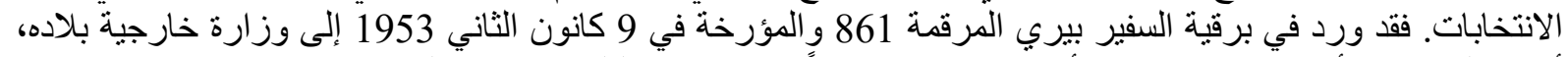

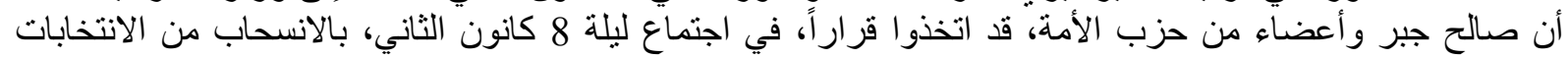


المقبلة، و اتهم رجال صالح جبر الحكومة بتدخلها ضد مرشحين مو الين لحزب الأمة في السليمانية واربيل والعمارة

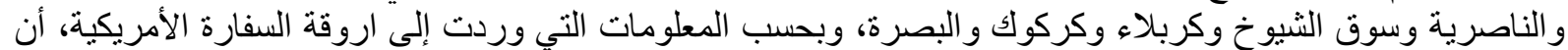

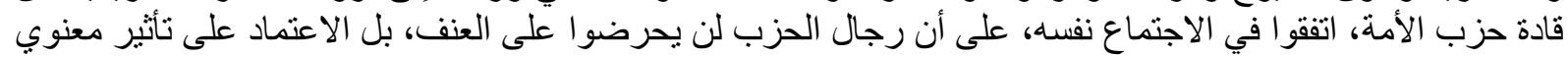

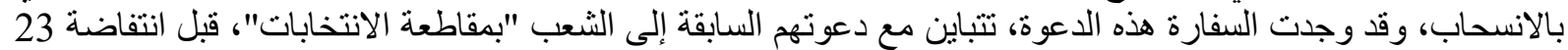

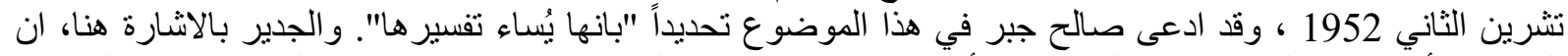

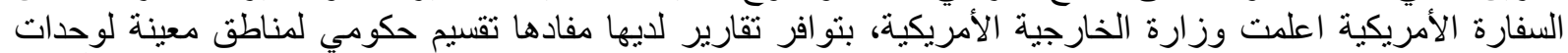

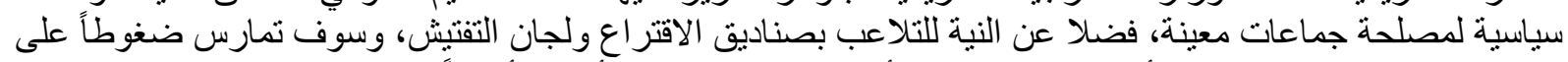

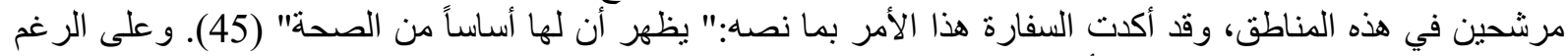

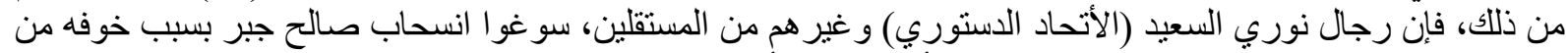

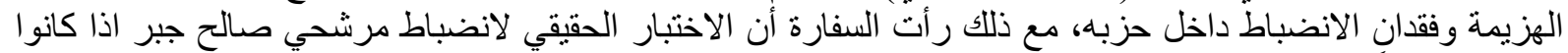

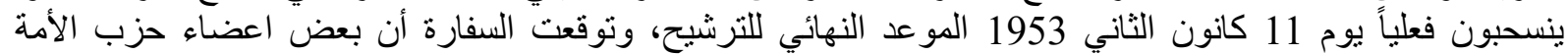

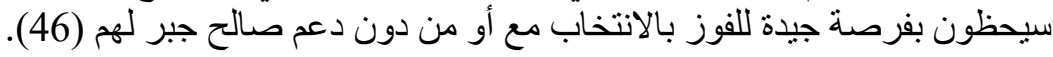

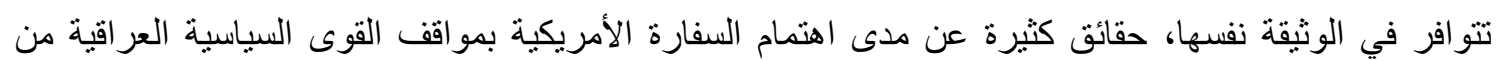

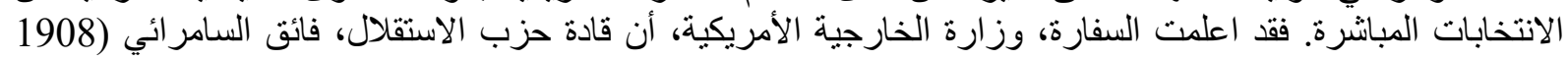

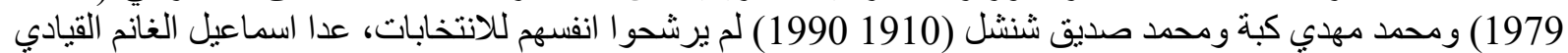

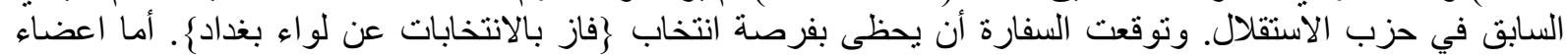

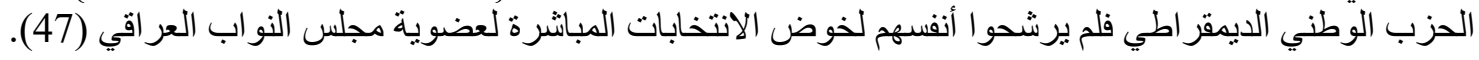

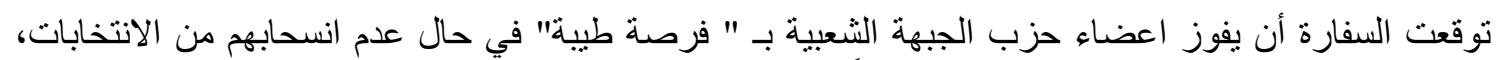

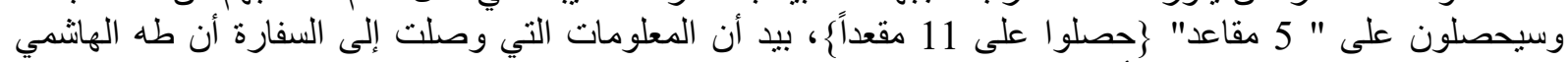

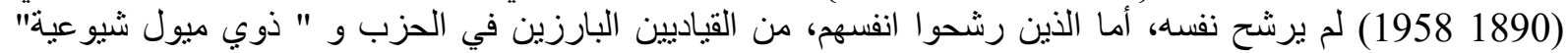

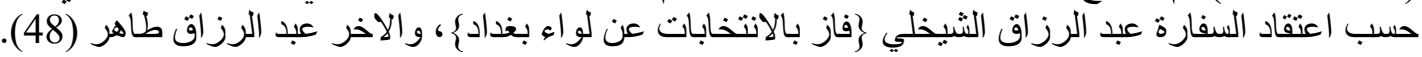

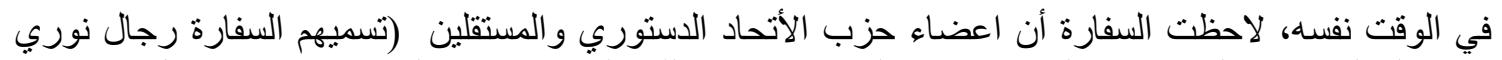

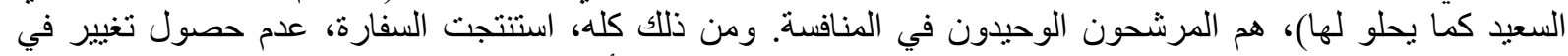

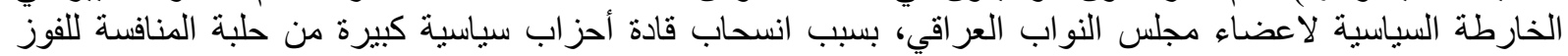

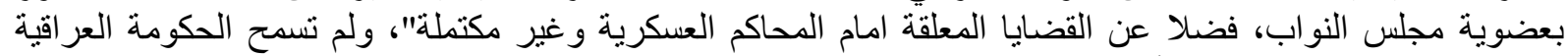

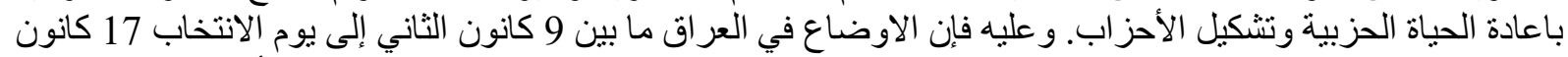

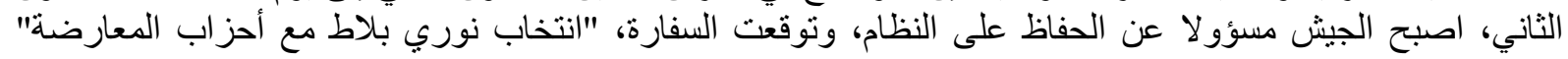

حظيت الصحافة العراقية وتعليقاتها عن الانتخابات المبانشرة المقبلة، باهتمام خاص من لدن السفارة الأمريكية

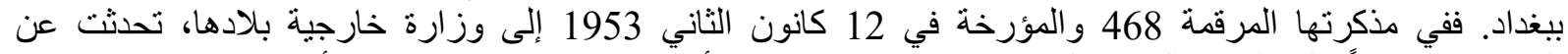

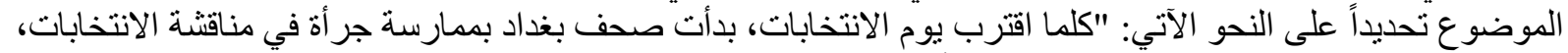

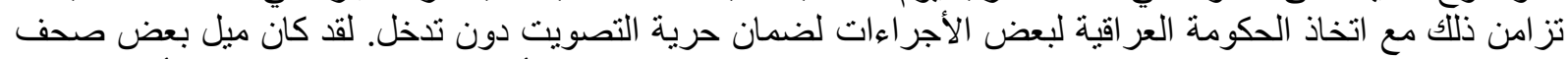

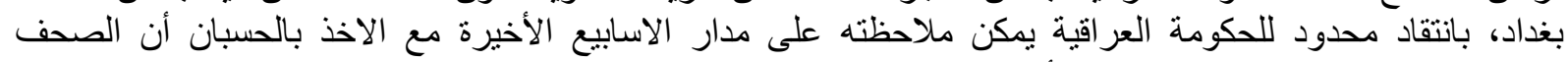

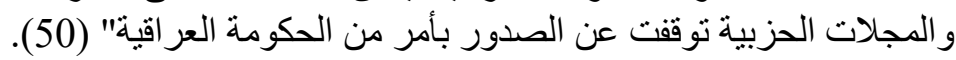

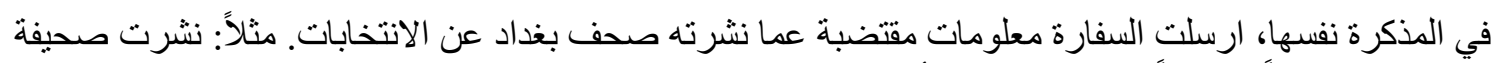

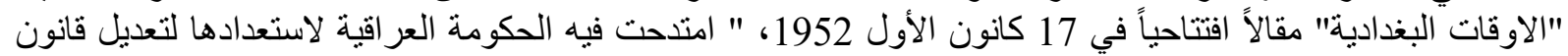

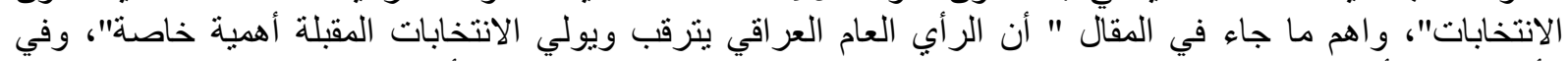

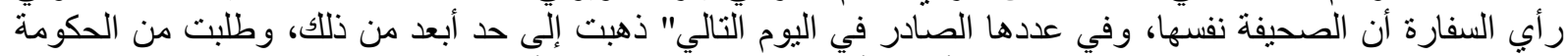

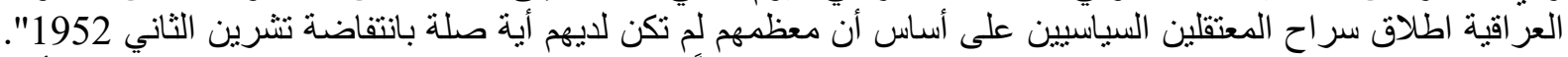

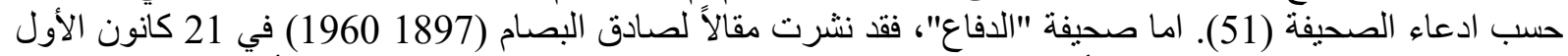

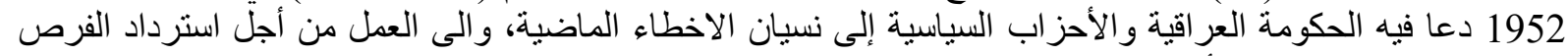

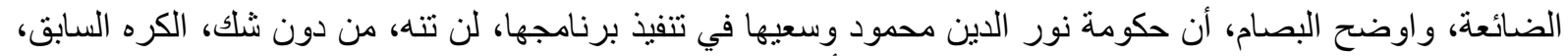

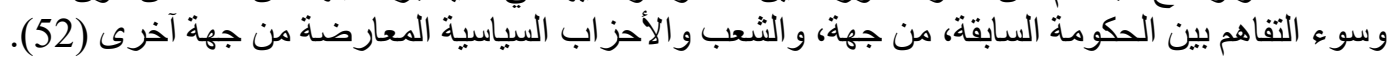

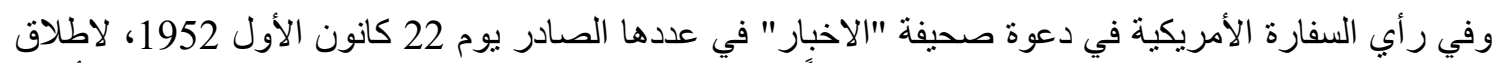

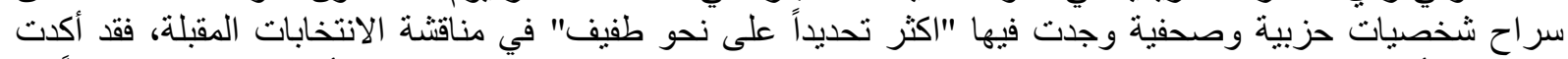

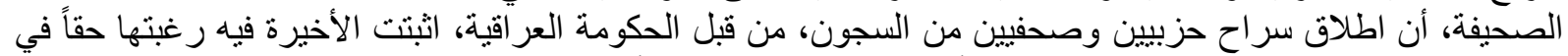

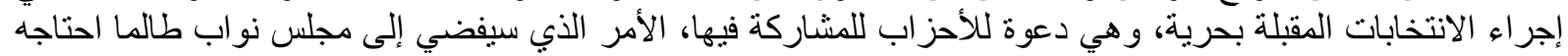

الشعب العر اقي (53). 


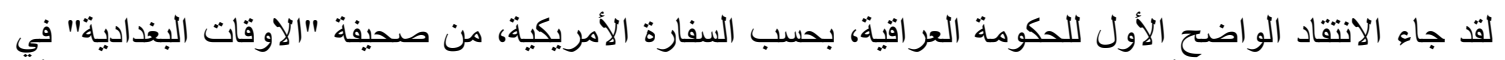

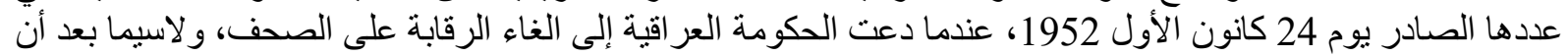

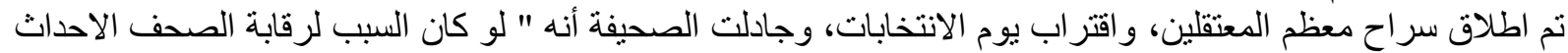

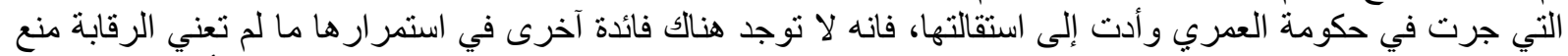

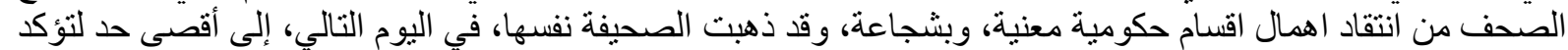

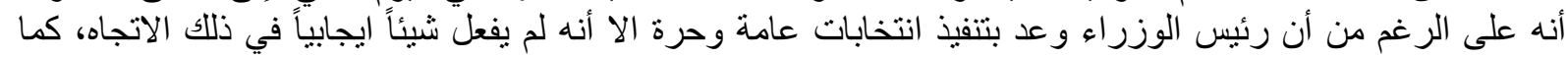

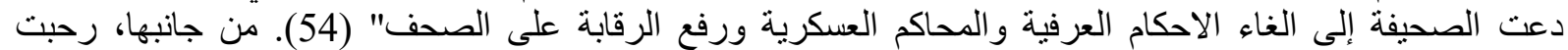

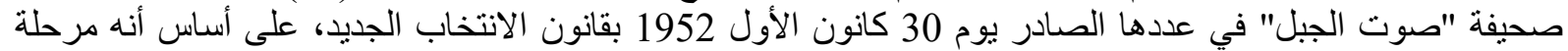

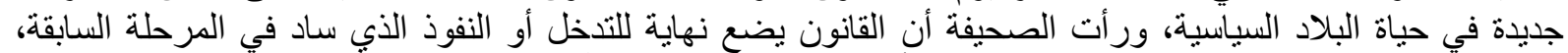

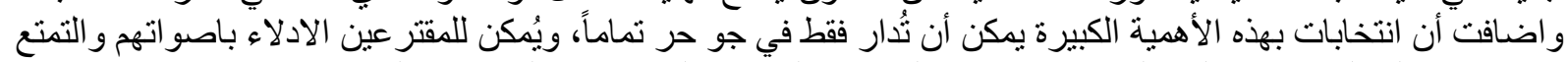

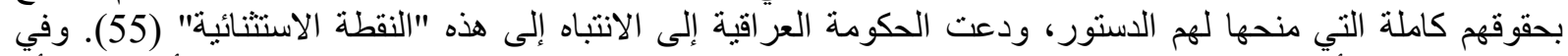

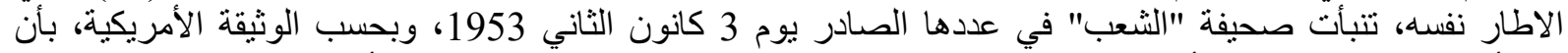

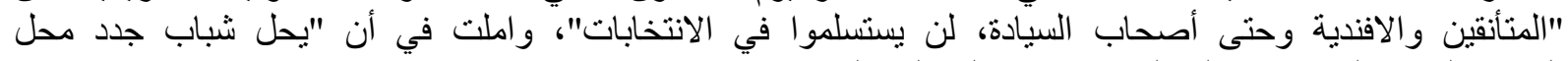

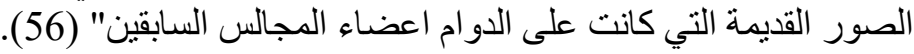

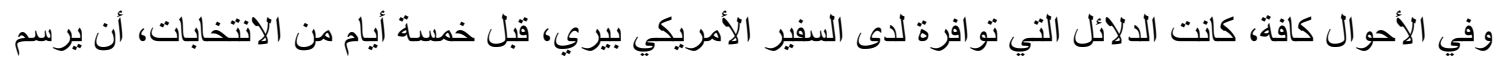

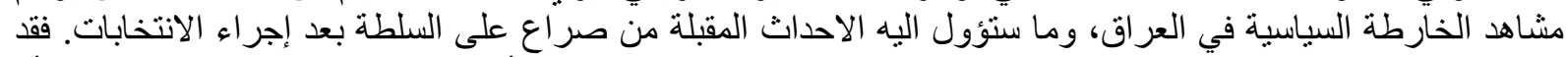

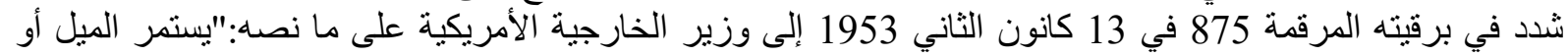

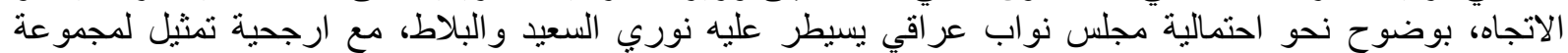

معارضة من حزب الجبهة الثعبية فقط" (57).

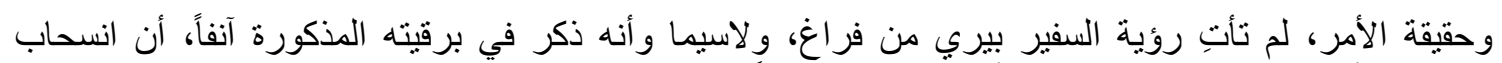

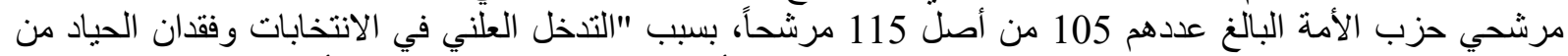

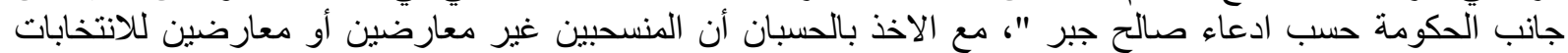

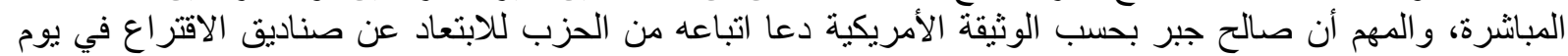

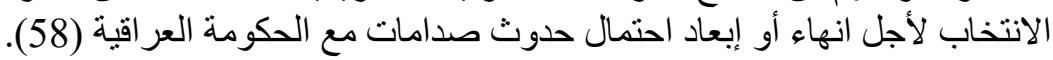

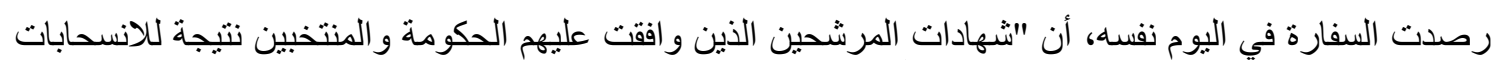

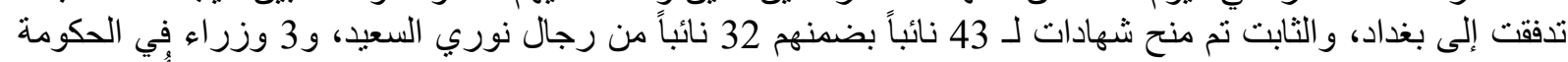

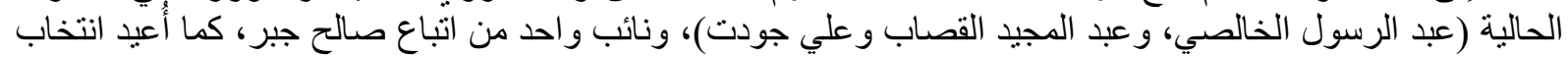

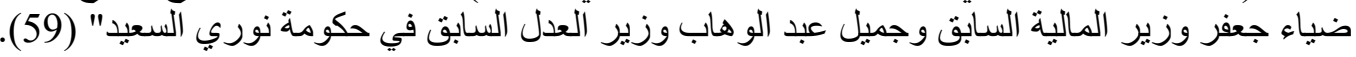

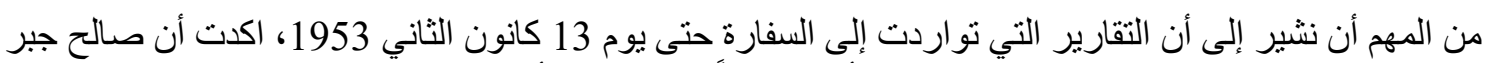

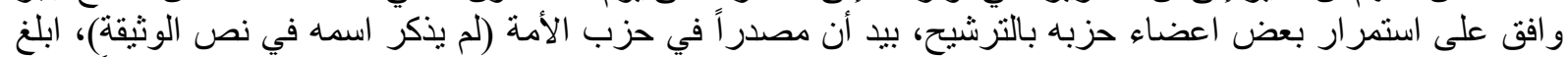

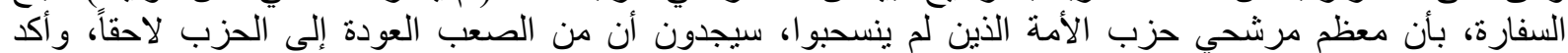

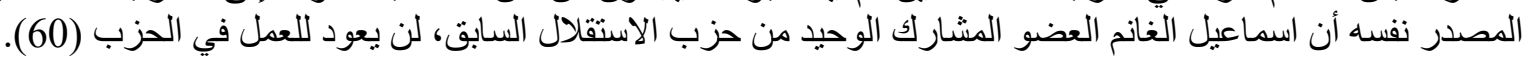

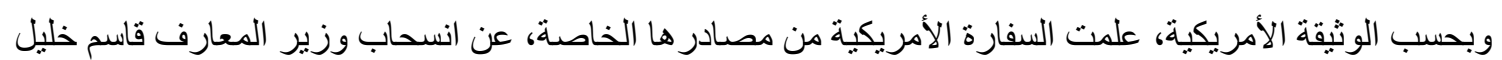

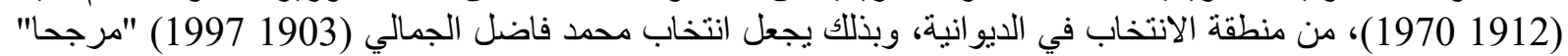

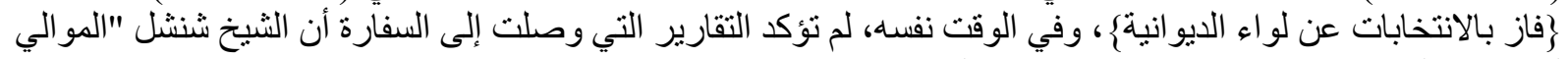

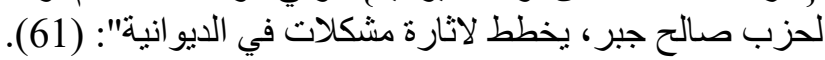

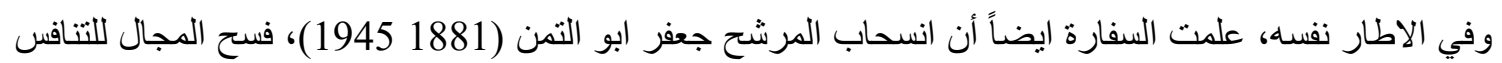

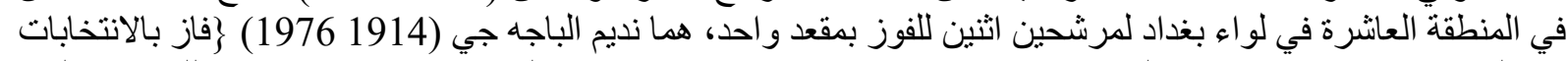

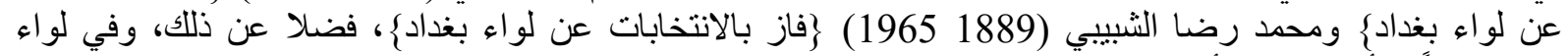

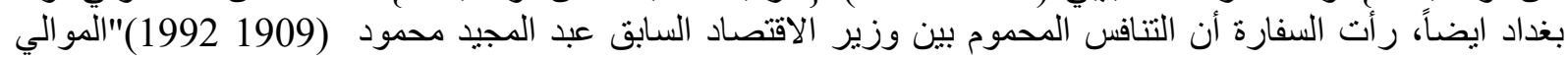

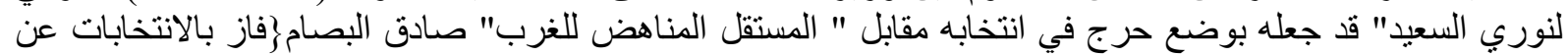

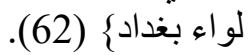

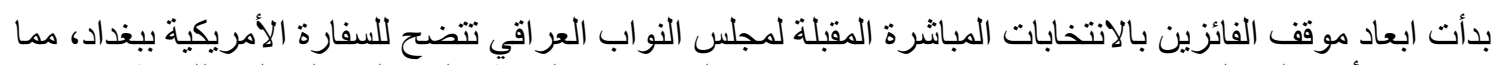

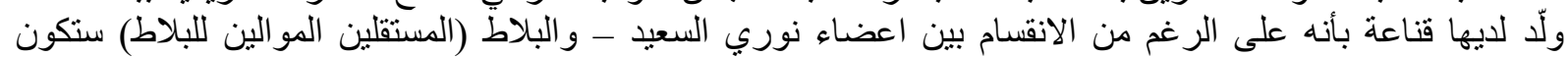

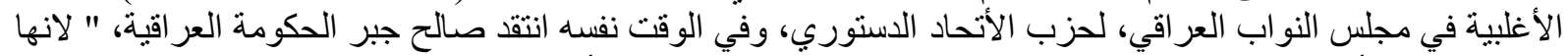

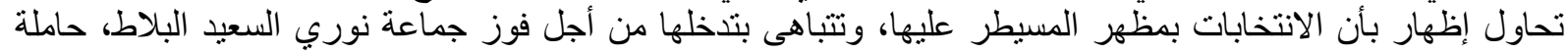

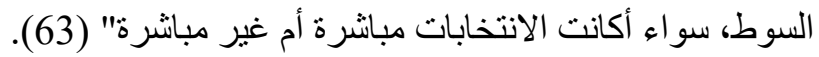

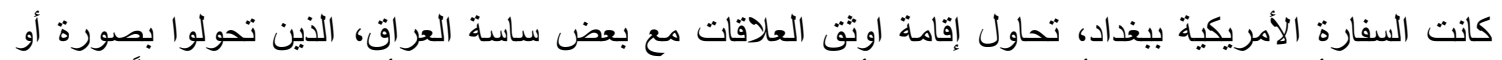

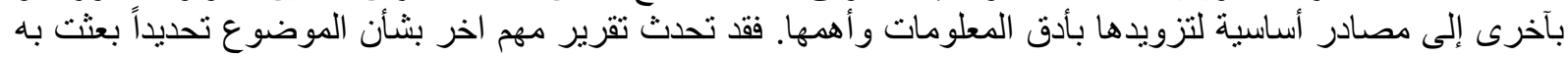




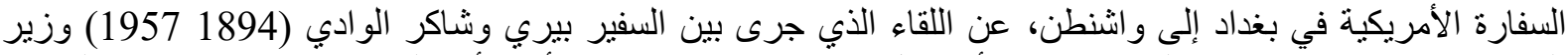

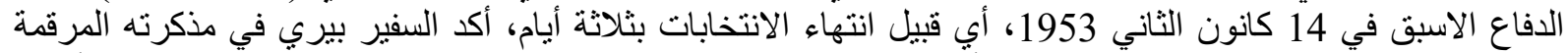

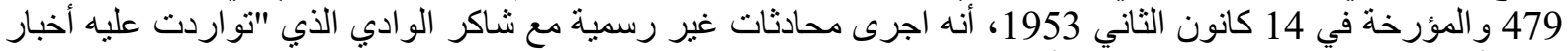

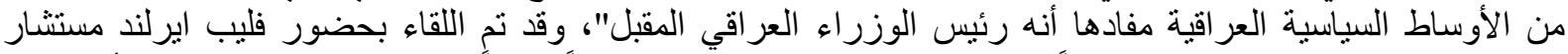

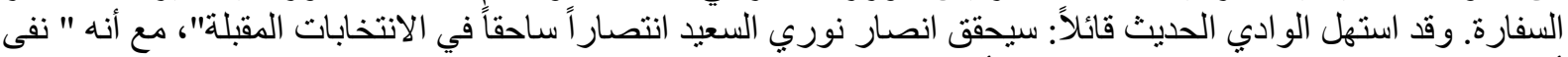

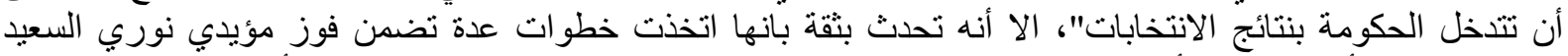

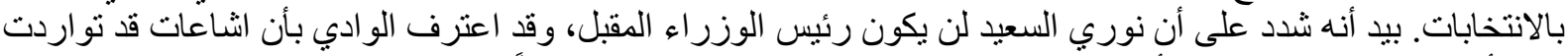

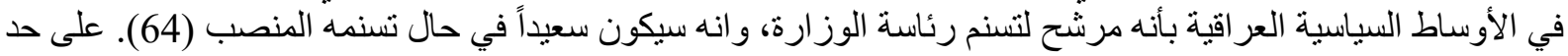
تعبير الوثيقة.

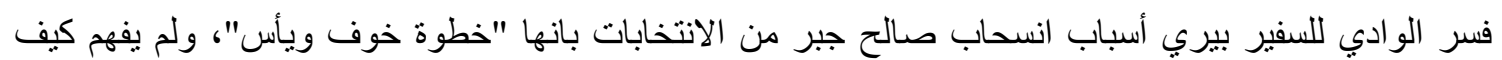

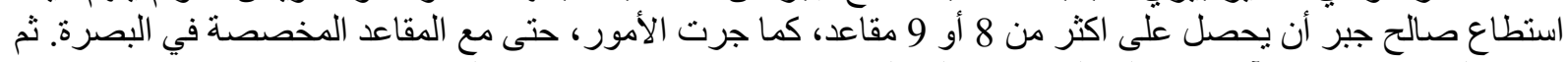

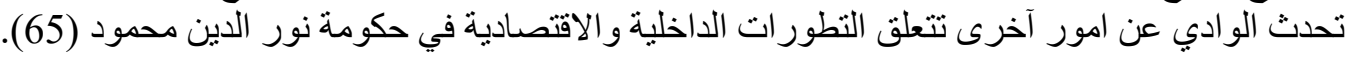

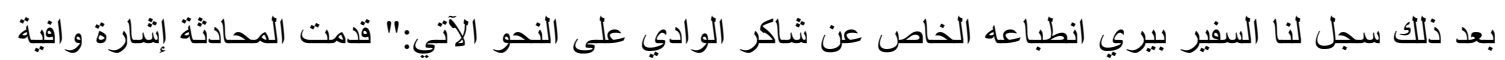

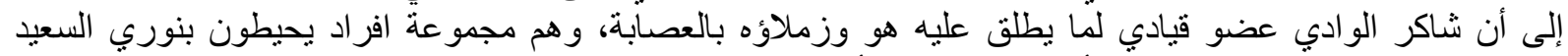

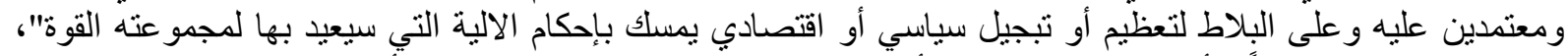

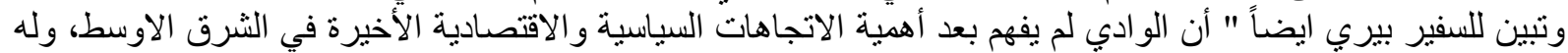

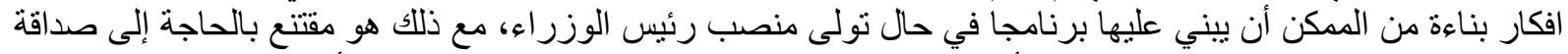

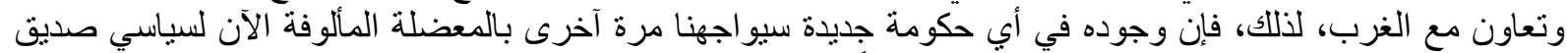

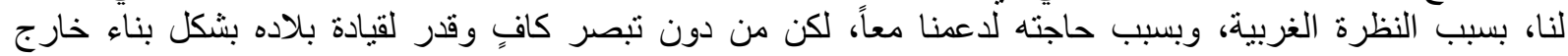

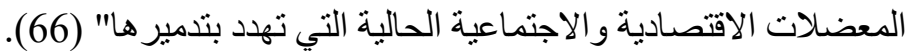

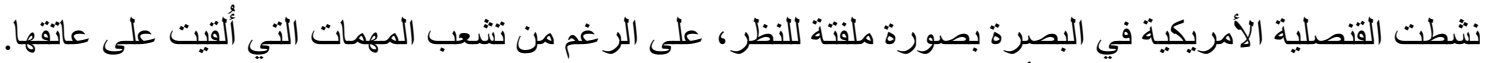

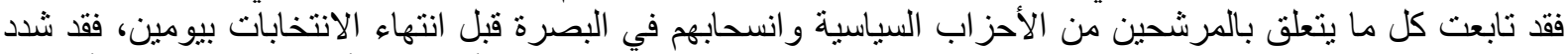

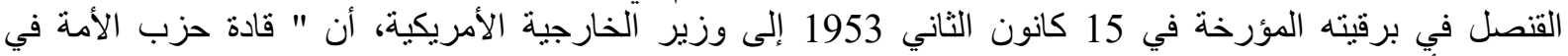

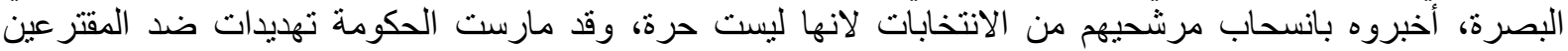

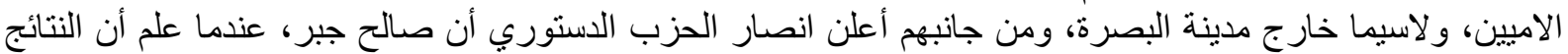

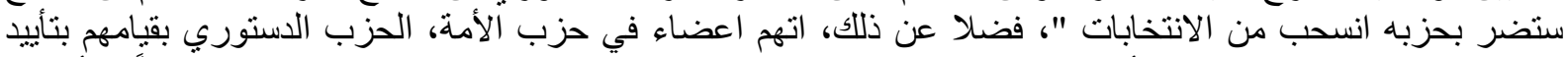

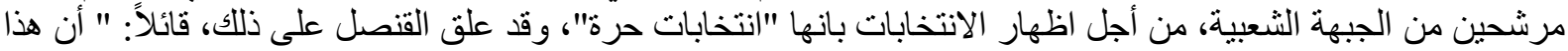

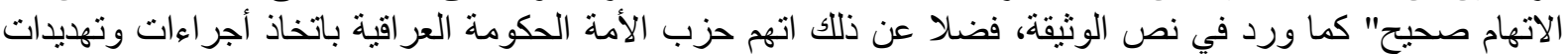

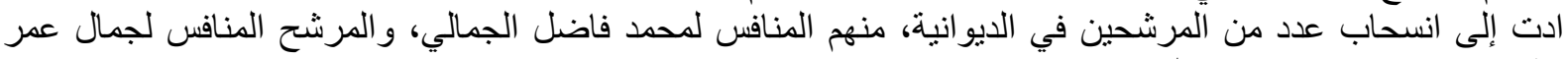

نظمي في قضاء رانية في اربيل (67).

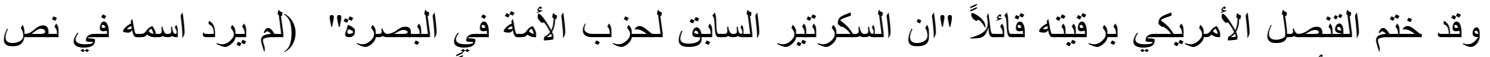

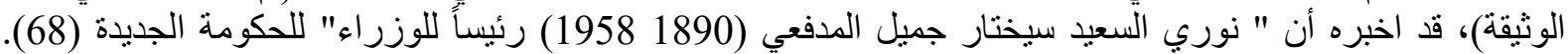

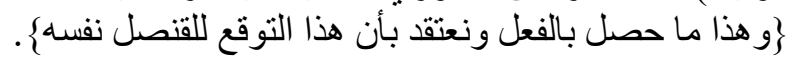

نجحت حكومة نور الدين محمود في احتواء المطلب الأول للشعب العرافي وقواه الفواه السياسية الفاعلة على الساحة

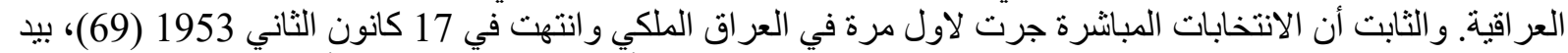

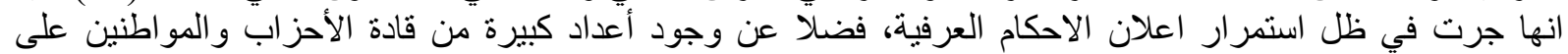

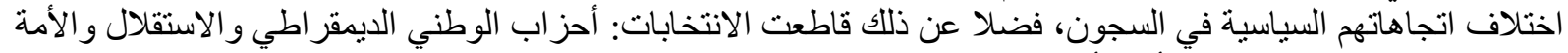

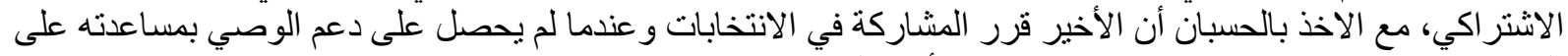

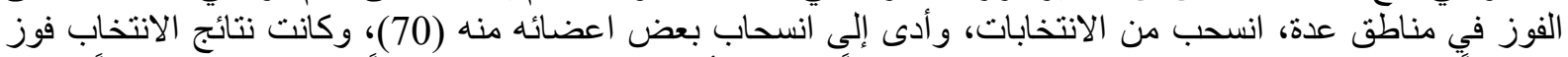

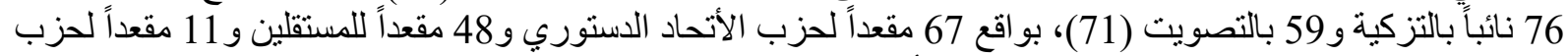

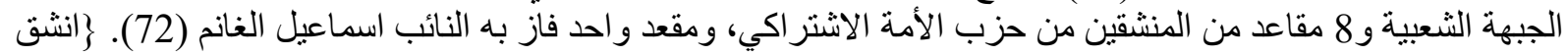

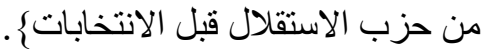

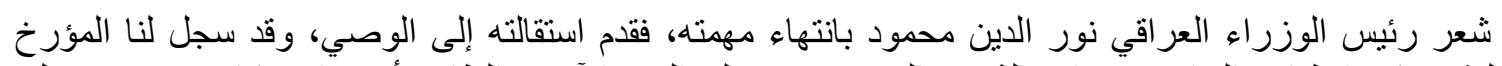

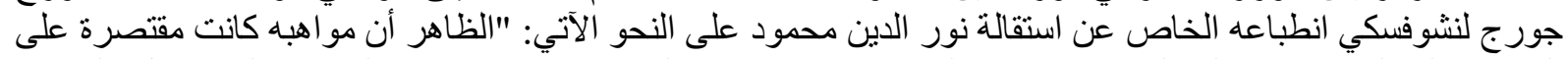

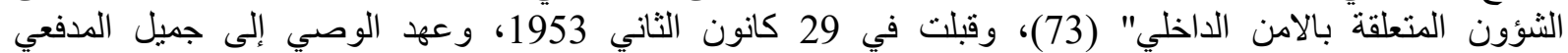

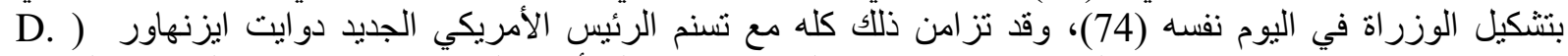
1953 Eisenhower

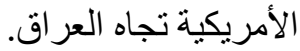




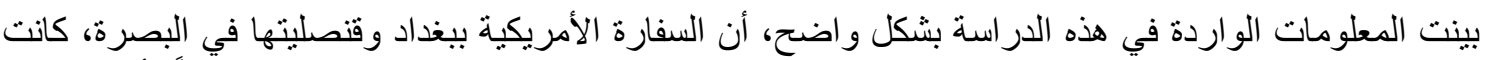

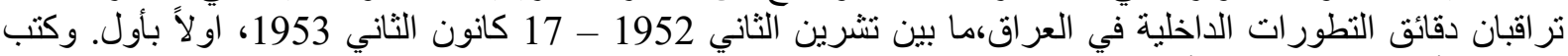

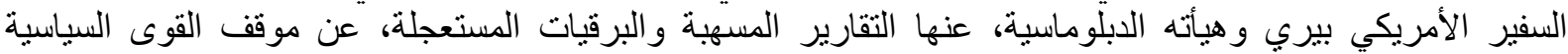

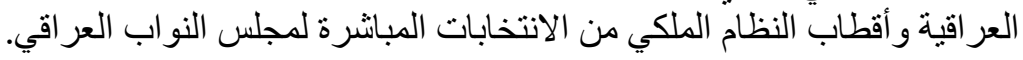

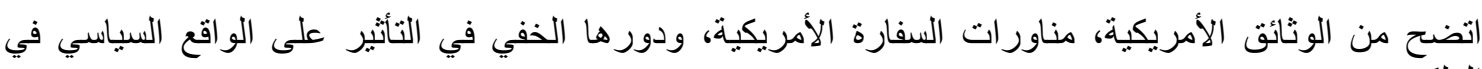
العراق الملكي. كثفت الدراسة أن عدداً من الساسة العراقيين في العهد الملكي، كانوا يرنون إلى إقامة أفضل العلاقات الطيبة مع إنها

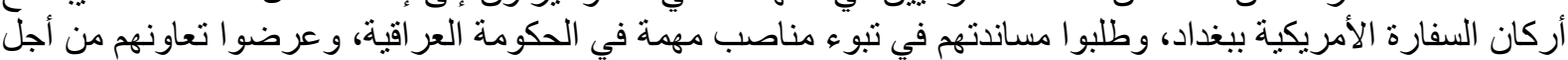
مصالحهم الثخصية.

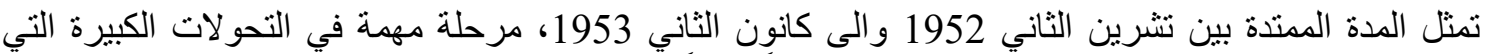

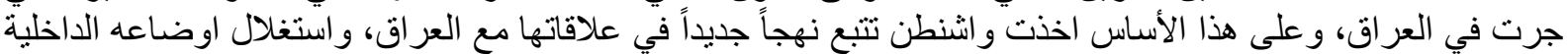

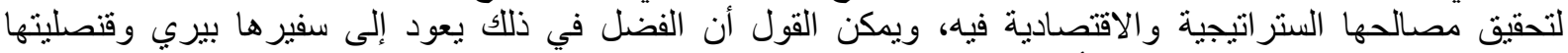

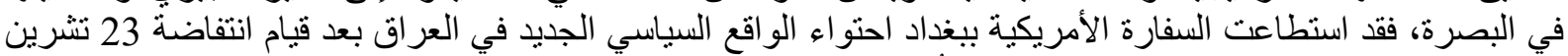

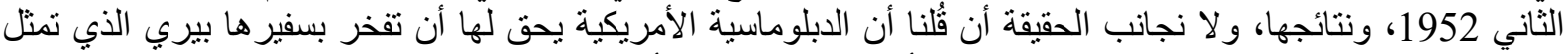

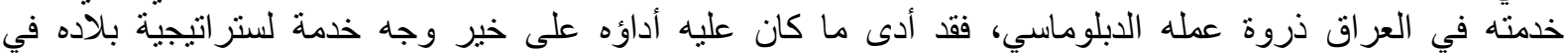
مرحلة تاريخية حاسمة من جميع الأوجه. 


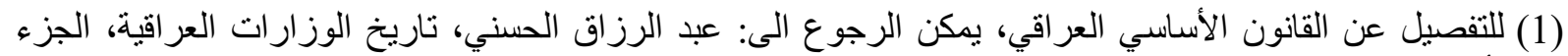

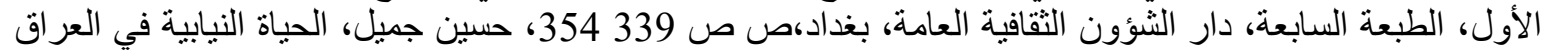

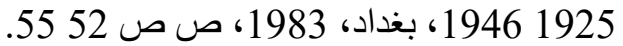

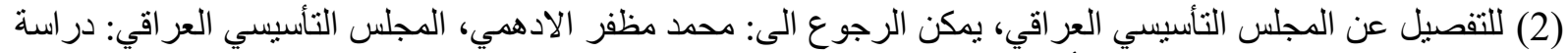

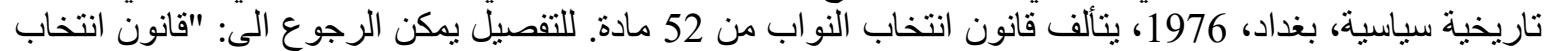
النو اب"، مطبعة الحكومة، بغداد، 1976، 1924. (ينظر : الملحق).

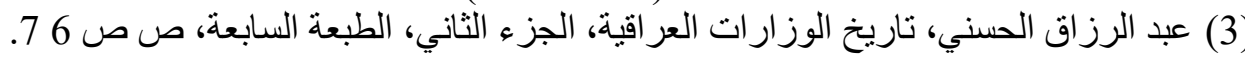

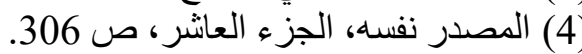

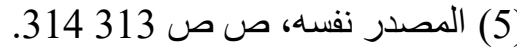

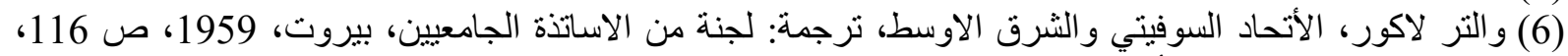

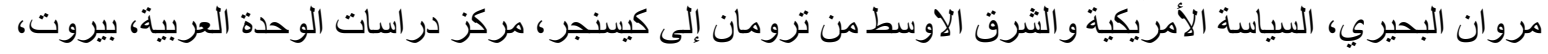

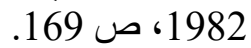

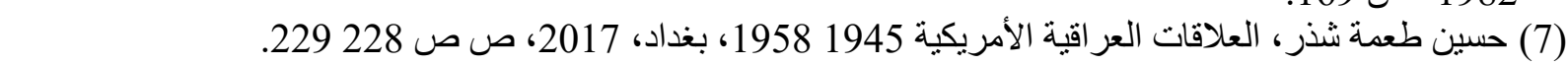

(865) جعفر عباس حميدي، التطورات السياسة في العراق 1941 (7) 1953، مطبعة النعمان - النجف الاشرف، 1958، 1976، ص .665

(9) (10) عبد الرزاق الحسني، تاريخ الوزارات العر اقية، الجزء الثامن، ص 2865.

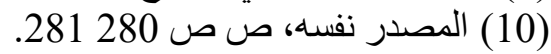

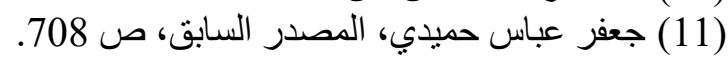

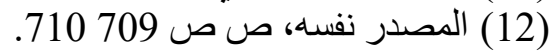

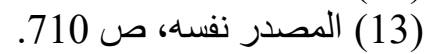

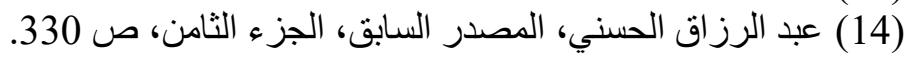

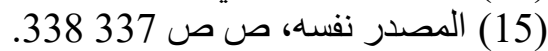

(16) U.S.D.S.C.F., No. 383, Despatch from American Embassy, Baghdad to the Department of State, Washington, Dec. 8 , 1952.

(17) Ibid.

(18) Ibid.

(19) Ibid.

(20) Ibid.

(21) Ibid.

(22) Ibid.

(23) Ibid, No. 371, Tel. from American Embassy, Baghdad to Secretary of State, Washington, Dec. $7,1952$.

$$
\text { (24) عبد الرزاق الحسني، ناريخ الوزارات العر اقية، الجزء الثامن، ص } 344 .
$$

(25) U.S.D.S.C.F., No. 383, Despatch from American Embassy, Baghdad to the Department of State, Washington, Dec. 8, 1952.

(26) Ibid, No. 761, Tel. from American Embassy, Baghdad to the of Secretary State, Washington, Dec. $13,1952$.

(27) Ibid.

(28) Ibid, No. 762, Tel. from American Embassy, Baghdad to the of Secretary State, Washington, Dec. $13,1952$.

(29) Ibid.

(30) Ibid.

(31) Ibid., No. 2821, Despatch from American Embassy, London to the Department of State, Dec. $15,1952$.

(32) Ibid.

(33) Ibid.

(34) Ibid.

(35) Ibid., No. 25, Despatch from American Consul to the Department of State, Dec. 15 , 1952. 
(36) Ibid., No. 405, Despatch from American Embassy, Baghdad to the Department of State, Washington,Dec.16, 1952.

(37) Ibid.

(38) Ibid., No. 814, Tel. from American Embassy, Baghdad to the Secretary of State, Washington,Dec.26, 1952.

(39) Ibid., No. 828, Tel. from American Embassy, Baghdad to the Secretary of State, Washington,Dec.30, 1952.

(40) Ibid., No. 828, Letter from American Consul to the American Ambassdor, Baghdad January 8, 1953.

(41) Ibid.

(42) Ibid.

(43) Ibid.

(44) Ibid.

(45) Ibid., No. 816, Tel. from American Embassy, Baghdad to the Secretary of State, No. 861,January 9 , 1953.

(46) Ibid.

(47) Ibid.

(48) Ibid.

(49) Ibid., No. 468, Memo. from the American Embassy, Baghdad to the Department of State, January $12,1953$.

(50) Ibid.

(51) Ibid.

(52) Ibid.

(53) Ibid.

(54) Ibid.

(55) Ibid.

(56) Ibid.

(57) Ibid., No. 875, Tel. from the American Embassy, Baghdad to the Secretary of State, January $13,1953$.

(58) Ibid.

(59) Ibid.

(60) Ibid.

(61) Ibid.

(62) Ibid.

(63) Ibid.

(64) Ibid., No. 479, Despatch from the American Embassy, Baghdad to the Department of State, January $14,1953$.

(65) Ibid.

(66) Ibid.

(67) Ibid., Tel., from the American Consul to the SEcretary of State, January 15, 1953.

(68) Ibid.

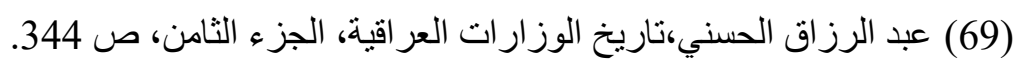

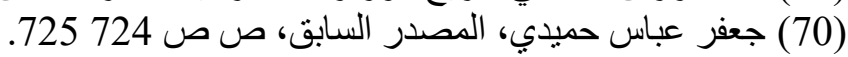

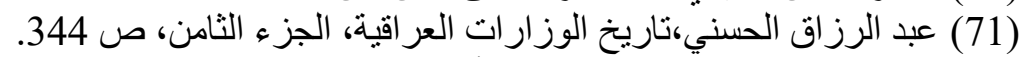

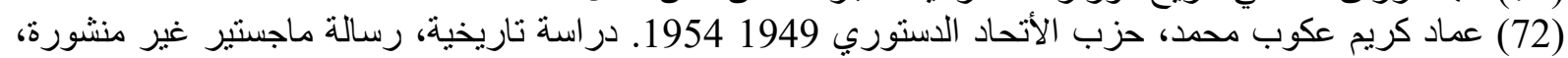

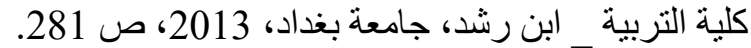

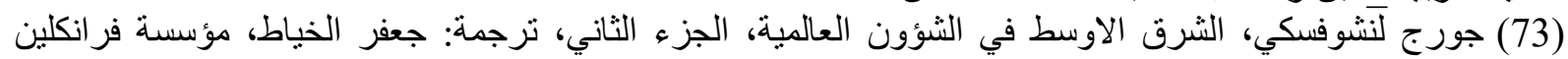

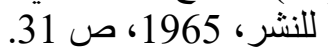

$$
\begin{aligned}
& \text { (74) عبد الرزاق الحسني، تاريخ الوزارات العر اقية، الجزء التاسع، ص ص } 67 .
\end{aligned}
$$


U.S. Department of stat, Condenal Files.

$$
\text { أولاً: الوثائق الأمريكية السرية غير المنشورة " وزارة الخارجية الأمريكية" }
$$

No. 383, Despatch from American Embassy, Baghdad to the Department of State, Washington, Dec. $8,1952$.

No. 371, Tel. from American Embassy, Baghdad to Secretary of State, Washington, Dec. 7 , 1952.

No. 761, Tel. from American Embassy, Baghdad to the of Secretary State, Washington, Dec. $13,1952$.

No. 762, Tel. from American Embassy, Baghdad to the of Secretary State, Washington, Dec. $13,1952$.

No. 2821, Despatch from American Embassy, London to the Department of State, Dec. 15 , 1952.

No. 25, Despatch from American Consul to the Department of State, Dec. 15, 1952.

No. 405, Despatch from American Embassy, Baghdad to the Department of State, Washington,Dec.16, 1952.

No. 814, Tel. from American Embassy, Baghdad to the Secretary of State, Washington,Dec.26, 1952.

No. 828, Tel. from American Embassy, Baghdad to the Secretary of State, Washington,Dec.30, 1952.

No. 828, Letter from American Consul to the American Ambassdor, Baghdad January 8, 1953.

No. 816, Tel. from American Embassy, Baghdad to the Secretary of State, No. 861,January 9 , 1953.

No. 468, Memo. from the American Embassy, Baghdad to the Department of State, January $12,1953$.

No. 875, Tel. from the American Embassy, Baghdad to the Secretary of State, January 13 , 1953.

No. 479, Despatch from the American Embassy, Baghdad to the Department of State, January $14,1953$.

Tel., from the American Consul to the SEcretary of State, January 15, 1953.

ثانياً: المطبو عات الحكومية

" قانون انتخاب النواب "، مطبعة الحكومة، بغداد، 1924.

ثُالثاً: الكتب باللغةة العربية والمعربة:

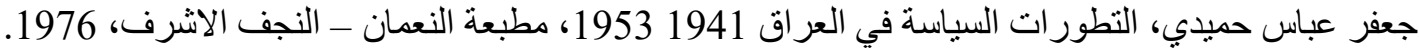

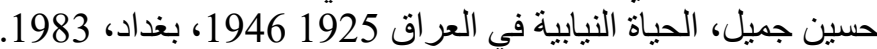

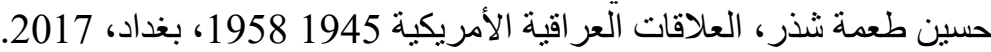

جورج لنشوفسكي، الثرق الاوسط في الثؤون العالمية، الجزء الثناني، ترجمة: جعفر الخياط، مؤسسة فرانكلين للنشر، .1965

عبد الرزاق الحسني، تاريخ الوزارات العراقية، الجزء الأول والثاني والثامن والتاسع والعانشر، دار الثؤون الثقافية

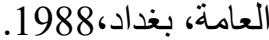

محمد مظفر الادهي، المجلس التأسيسي العر اقي: دراسة تاريخية سياسية، بغداد، 1976.

مروان البحيري، السياسة الأمريكية والثرق الآوسط من ترومان إلى كيسنجر، مركز دراسات الوحدة العربية، بيروت، . 1982

و التر لاكور، الأتحاد السوفيتي والثرق الاوسط، ترجمة: لجنة من الاساتذة الجامعيين، بيروت، 1959. 


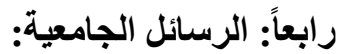

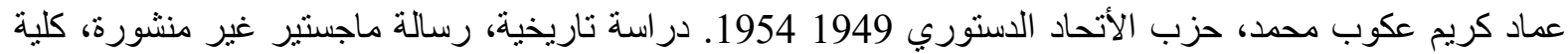
التربية_ ابن رشد، جامعة بغداد، 2013. 